\title{
Widening the application of AATSR SST data to operational tasks through the Medspiration Service
}

\author{
Ian Robinson ${ }^{\mathrm{a},{ }^{*}}$, Jean-Francois Piollé ${ }^{\mathrm{b}}$, Pierre LeBorgne ${ }^{\mathrm{c}}$, David Poulter $^{\mathrm{a}}$, Craig Donlon ${ }^{\mathrm{d}}$, Olivier \\ Arino $^{\mathrm{d}}$
}

\author{
a National Oceanography Centre, Southampton, School of Ocean and Earth Science, University of Southampton \\ Waterfront Campus, European Way, Southampton SO14 3ZH, UK \\ ${ }^{\mathrm{b}}$ CERSAT, IFREMER, BP70, 29280, Plouzané, France \\ c Centre Météorologie Spatiale, BP.147, 22302 Lannion, France \\ ${ }^{\mathrm{d}}$ European Space Agency, ESRIN, via Galileo Galilei, CP 64, 00044 Frascati, Italy
}

"Corresponding author : Ian Robinson, Tel.: + 44238059 3438, email address : isr@noc.soton.ac.uk

\begin{abstract}
:
For over a decade the ATSR series of sensors produced high quality SST data products, but the narrow swath did not encourage their use for operational tasks. This changed in 2005 when the European Space Agency's Medspiration Service introduced AATSR data in the GHRSST L2P format. This paper describes the opportunities provided by the Medspiration system for facilitating the complementary use of SST products from AATSR and from other satellite sensors. It explains how, following the implementation by Medspiration of GHRSST procedures, data products and tools, AATSR data are now being used around the world to complement the use of other sources of SST and to facilitate bias adjustments between them. Despite the limited daily coverage of AATSR its broadly reliable accuracy and stability seem to be beneficial to SST analyses that merge all available observations. The new analyses are already contributing to improved ocean and weather forecasting. This represents an unforeseen but significant role for the ATSR series, through which it continues to make an important contribution to the operational uses of SST.
\end{abstract}

\section{Highlights}

The Medspiration Project pioneered operational SST data to GHRSST specification. It demonstrated the utility of a matchup database for evaluating SST data quality. I It developed a high resolution diagnostic dataset for comparing SST products. - Producing AATSR SST data in GHRSST L2P form led to new operational applications. AATSR data are routinely used in several global analyses of sea surface temperature.

Keywords: Sea surface temperature; Operational Oceanography; AATSR; Medspiration Service; Group for high resolution sea surface temperature (GHRSST) 


\section{AATSR and high resolution SST mapping requirements}

The accurate mapping of sea surface temperature (SST) provides the foundation for a range of tasks that have become the responsibility of operational monitoring and forecasting agencies in the 21st century. For example, regularly updated knowledge of SST is needed for numerical weather prediction (Chelton and Wentz, 2005; Chelton, et al., 2007), and the search for improved weather forecasts requires SST to be observed at finer spatial resolution, more frequently and with timely delivery. Ocean forecasting models that assimilate SST observations are increasingly being used operationally for various applications including maritime safety, military operations, ecosystem assessment, fisheries support and tourism (Bell, et al., 2000; Johannessen, et al., 2006). Estimates of the flux of heat, momentum and gases between the ocean and atmosphere rely on knowledge of SST. Well defined and error-quantified measurements of SST are also required for climate time series that can be analysed to reveal the role of the ocean in short and long term climate variability (Reynolds, et al., 2002).

The minimum specification for global scale measurements of SST in support of the diverse applications outlined above were defined by the Global Ocean Data Assimilation Experiment (GODAE), stating that SST observations with global coverage, a spatial resolution of $10 \mathrm{~km}$ and an accuracy of $0.2^{\circ} \mathrm{C}$ need to be updated every $6 \mathrm{~h}$ (Smith and Koblinsky, 2001). This measurement capability is required to provide a near-real time synoptic view of upper ocean mesoscale variability, which effectively constrains numerical models of upper ocean circulation and thermal structure. Although there is a network of SST observations from ships and buoys, the only way to meet and exceed this demanding specification is to use measurements of SST from earth observation satellites.

This paper explores the extent to which the series of Along-track Scanning Radiometers (ATSR, ATSR-2 and AATSR) flown respectively on the European Space Agency (ESA) satellites ERS-1 
(1991-1996), ERS-2 (1995-2008) and Envisat (2002 - present), have a contribution to make to the high resolution daily monitoring of global SST, and whether AATSR is capable of delivering the near-real time measurements that are required to support the operational ocean nowcasting and forecasting systems outlined above. This question is pertinent because, although the design of ATSR was targeted at achieving SST measurements with high absolute accuracy to support climate science, the narrow swath of only $500 \mathrm{~km}$ gives the sensor a global revisit interval of several days which is markedly inferior to other satellite based SST measurement systems and might seem to rule it out from serving the needs of operational ocean monitoring.

The ATSR class of sensors (Edwards, et al., 1990) operates in the infra-red and scans conically, making two independent observations of each part of the sea surface within the narrow swath, through different atmospheric path lengths. Having two spectral windows within the $10.0-12.5 \mu \mathrm{m}$ atmospheric window and another centred on $3.7 \mu \mathrm{m}$, the sensor can make six independent measurements of brightness temperature for each pixel viewed at night and four in daylight when the $3.7 \mu \mathrm{m}$ channel cannot be used. The extra channels from the dual view yield additional information about atmospheric transmission effects leading to an improved atmospheric correction procedure (Závody, et al., 1995). This has proved to be robustly sensitive not only to the effect of water vapour but also to stratospheric aerosols (Merchant and Harris, 1999; Merchant, et al., 1999). Independent validation of the AATSR series has demonstrated the quality and reliability of the dual-view SST products (Parkes, et al., 2000; Corlett, et al., 2006; Noyes, et al., 2006; O'Carroll, et al., 2006; O'Carroll, et al., 2008), while a sustained validation campaign in comparison with ship based radiometry over 5 years confirms the stability of its absolute accuracy (Wimmer, et al., 2011), at least in the Bay of Biscay and English Channel region.

The enhanced accuracy of the ATSR series has led to its leading role in the development of a climate-quality time series for SST (Merchant, et al., 2008b). Additionally the potential of ATSR 
for wider scientific applications was recognised in the years following its commissioning (Murray, et al., 1998), leading to the results presented elsewhere in this AATSR Special Issue. Nonetheless, during the first twelve years of the ATSR series its global impact, beyond the narrow SST community directly connected to the mission, was disappointingly small. This situation can be attributed first to the slow rate at which the ATSR data products were made available to the global SST community, but even when the data became more widely accessible; potential users were discouraged by the poor coverage resulting from the narrow swath, dictated by the dual view design needed to achieve high accuracy.

However, in the last six years the situation has changed. The level 2 dual-view SST data products from AATSR are now being used widely and have been instrumental in encouraging the development of a number of new global high resolution SST analysis datasets competing to meet the GODAE requirements expressed above. Moreover, the global SST community, through the Group for high resolution SST (GHRSST) (Donlon, et al., 2007) have strongly articulated a requirement for the AATSR class of sensors to be sustained beyond the lifetime of Envisat, in order to protect the performance of the operational applications for which global high resolution SST products are now being utilised.

It is the purpose of this paper to explain what lies behind this renewed interest in using AATSR data, in particular the important role that has been attached to it for supporting SST applications in operational oceanography. The emergence of GHRSST in 2001-2005 as the forum for global co-operation in the development of satellite SST measurements provided the context in which AATSR data have come to be more widely adopted. The specific instrument which made this possible was a project sponsored by ESA within its Data User Element (DUE), which is intended to encourage the establishment of a long-term relationship between user communities and Earth Observation. The project, which ESA called Medspiration, established a prototype service for the purpose of demonstrating the practical implementation of the GHRSST principles. In 
doing so it facilitated the demonstration of ATSR-class datasets as essential inputs to high resolution SST products for operational applications. Section 2 provides the background to the Medspiration Project by summarising the GHRSST strategy for meeting the challenge of delivering high resolution SST suitable for operational needs. Section 3 identifies the new GHRSST-compliant SST data products and analytical tools produced by the Medspiration Project, which have been instrumental in facilitating the wider use of AATSR data. Section 4 uses the Medspiration / GHRSST tools to explore the variability between nearly coincident SST retrievals from different sensors, and shows how the quality of the AATSR data enables it to be used for bias adjustment. Section 5 explains how this has led to considerable improvement in the resulting SST analysis products, which can be attributed to the availability of AATSR data, mediated through the GHRSST methodology as demonstrated through the Medspiration project. 


\section{Meeting the challenge of global high resolution SST mapping}

\subsection{The diversity of sensor types for measuring SST from satellites}

Several types of systems are now in place for monitoring SST regularly from satellites (Robinson and Donlon, 2003), producing updated global or regional maps of SST every day from polar and geostationary platforms. These include infrared (IR) and microwave (MW) radiometers which have very different spatial and radiometric resolutions and are subject to different constraints such as opacity to clouds for IR and proximity to land or heavy rain for MW sensors. Figure 1 compares the typical daily global coverage of six different SST data products. Inspection of the available systems, their spatial resolution, geographical daily coverage and the accuracy of their products shows that none of the SST datasets delivered by individual sensors come close to meeting the GODAE sampling requirements, but a combination is more promising. In principle the strengths and weaknesses of each system can be offset against the others to produce a more complete, frequent and accurate SST analysis.

The underpinning strategy adopted by GHRSST was to exploit the complementary nature of the different SST datasets already being provided, rather than attempting to create a completely new product. Previously those with an operational or scientific need for SST would tend to use one or another of the data products as available from different agencies. Given the difficulty of combining data from sensors which inherently sample the SST in different ways, as well as the overhead costs of handling different formats and data delivery routes, operational users were normally constrained to choose the single particular product that best suited their needs. GHRSST concluded that in fact it was not possible to meet the demanding GODAE requirements without access to data from each of four distinct classes of satellite SST sensors / systems.

These classes are detailed in Table 1. Put simply, the polar-orbiting IR radiometers (class A) deployed primarily as meteorological sensors provide a global high resolution baseline map of 
SST both day and night, but this is seriously compromised by cloud. MW radiometers (class B) provide the only measurements in cloudy regions, but at much coarser spatial resolution than IR systems. In order to monitor rapidly-varying phenomena, including diurnal variability, IR sensors on geostationary platforms (class C) are needed, although global coverage is incomplete because high latitudes are inaccessible. Finally it was concluded that, in order to meet the accuracy requirements when data from these three classes of SST system are blended together, there is a need for another class of sensor, class $D$, whose principal characteristic is that it reliably delivers high accuracy and stability of SST retrieval. From the GHRSST perspective its primary role is to provide SST products that can serve as a more stable reference against which to compare the other SST products. In this capacity it is not a serious problem if it has a longer revisit interval than the other SST products, provided it has global reach. The ATSR, an IR radiometer with enhanced atmospheric correction and robust to long-term changes in stratospheric aerosols, fits this role effectively when used in its dual view mode.

From the foregoing it is evident that a complementary approach, which seeks to maximise the benefits from all available sources of SST data, should be preferable to a selective strategy that simply attempts to pick the "best" SST data product from a particular sensor. Nonetheless, an approach which seeks to blend data from several sources and types of sensor must overcome a number of obstacles if it is to produce SST data that are of higher quality than the constituent source datasets. There can only be a meaningful role for ATSR-class data if these practical issues can be resolved, as discussed in the next subsection.

\subsection{Data merging problems addressed by the GHRSST approach}

The challenge facing GHRSST was to make it possible for the separate SST datasets from the different types of sensor, produced by different agencies, to be readily used together. The most obvious practical obstacle is that the different file formats and metadata standards used by 
agencies producing SST data made it expensive and time consuming for operational users to ingest more than one type of SST input. In practice operational users have tended to select one and ignore the rest. This often ruled out ATSR as a serious contender due to its long revisit interval. In order to avoid this problem GHRSST made it an absolute requirement that all data, whatever their primary source, should be made available as netCDF files with a common format and metadata definitions.

However, the problem of SST data harmonisation goes deeper than incompatible formats and metadata, or coping with different spatial and temporal sampling intervals. It must also face the reality that sea surface temperature is not as simple a scientific concept as it might first seem. Different sensor types record different aspects of the variable temperature structure of the surface layers of the ocean. In low wind conditions solar radiation tends to heat the top few metres of the sea during the day, but this stratification disappears at night as the surface loses heat - a phenomenon known as the diurnal thermocline. Additionally there is a thin layer of water a few tens of microns thick that is cooler than the water beneath. Consequently the term "SST" has slightly different meanings according to how it is measured (Robinson and Donlon, 2003). GHRSST defines and distinguishes between the skin SST, which is the temperature in the upper $10 \mu \mathrm{m}$ of the surface water as measured by an IR radiometer, the sub-skin SST at a depth of a few mm which is measured by a MW radiometer, and the foundation SST which is the temperature at the base of the diurnal thermocline, if present (Donlon, et al., 2007). In practice the foundation SST is the same as the sub-skin SST measured at dawn assuming that any diurnal thermocline from the previous day has collapsed during the night.

All satellite measurements, irrespective of how they are calibrated, physically detect either skin or sub-skin SST. However, users of SST typically require knowledge of the foundation SST since this broadly corresponds to the temperature of the ocean's upper mixed layer. It is what is normally represented by the temperature of the top layer of an ocean model and it characterises 
the heat content of the upper ocean layer, although for estimating heat flux through the air-sea interface the skin or sub-skin temperature is more suitable. The GHRSST approach is therefore to present SST products that represent individual measurements from satellites as skin or subskin temperatures. In contrast, when SST is estimated as an analysis of several independent satellite retrievals from different sensors and different times of the day, it is often specified as a foundation temperature. This is appropriate since physically the foundation temperature is a more stable property that does not fluctuate rapidly in time and space like the skin or sub-skin does during diurnal warming or when the wind stress changes.

Before individual satellite observations can be merged to produce an analysed SST, or assimilated into an ocean model, they must be converted into the corresponding foundation SST, by applying estimates of the diurnal warming. This is problematic, since models of diurnal variability are still uncertain (Stuart-Menteth, et al., 2005; Merchant, et al., 2008a). However, if diurnal warming is to be estimated, or else if the presence or absence of a diurnal warm layer is to be flagged, information is needed about the wind speed and the solar irradiance around the time that the SST was measured. There may be other factors that also affect the interpretation of a satellite SST record, such as the amount of sea ice in a high latitude region. For this reason, the GHRSST data model (Donlon, 2006) recommends that pixel-by-pixel ancillary information is attached to SST data from their original producer when being reformatted into the new GHRSST product specification. Just as essential is to add pixel-level quality information, including sensor specific error statistics and confidence flags (e.g., describing engineering parameters, data processing choices, quality indicators), that are needed by operational users.

\subsection{The GHRSST Product Strategy}

Based on the considerations outlined above, the GHRSST Pilot Project developed a data strategy of defining two distinct types of SST product. The first is based on the primary SST outputs generated by the agencies responsible for individual SST sensors and missions. These 
are generally level 2 products, consisting of image data from a single overpass, at the native spatial resolution of the sensor and normally in along-track and across-track satellite coordinates. Thus the corresponding GHRSST products are referred to as L2P ( $P$ for preprocessed). These CF-consistent netCDF files contain the SST records unchanged from those generated by the original agency, but they also append the error statistics, confidence flags, the sampled time and geographical location of each pixel, this being the minimum information set required to produce the $\mathrm{L} 2 \mathrm{P}$ Core product. The full $\mathrm{L} 2 \mathrm{P}$ products additionally contain the ancillary data fields discussed above. For some sensors, e.g. microwave radiometers, the primary SST product is already globally gridded, made up from several overpasses and therefore strictly a Level 3 product, and this is treated in the same way to form a GHRSST L3P product. The purpose of these new products is to supply SST data at the finest available resolution, treated as a skin or subskin measurement, with all the additional information needed for an operational service provider or scientific user to make use of it in near-real time, within minutes to a few hours of acquisition.

However, other users want to avoid the complication of combining data from different sources and would prefer a blended SST map from all the available sources. To satisfy this requirement, GHRSST has specified the Level 4 (L4) product. This type of product is an analysis of the data from several satellite sensors, and perhaps also in situ observations, and is treated as a foundation SST. While the GHRSST data model specifies the additional information that must be added as ancillary fields, it does not dictate the way in which the analysis is performed. This approach provides different agencies with the latitude to produce different L4 products using data selection and optimal interpolation procedures matched to particular user requirements.

Because of the importance of quality control for the successful development of a wide range of applications of SST data, GHRSST also identified two further products / services needed to 
support the activities of data providers. The first of these is a match-up database (MDB) which links in situ observations of SST to the most closely coincident satellite data pixel, needed for validating the sensor specific error statistics of each L2P product. The second is a high resolution diagnostic dataset (HR-DDS) in which small fields of data (typically $200 \mathrm{~km}$ square) are extracted from every GHRSST image product (L2P, L3P and L4) at a number of specified locations spread around the world and resampled into the same high resolution grid (typically 2 $\mathrm{km}$ ). Its primary purpose is for quality control, to facilitate intercomparison between the different source datasets of SST, and also for comparing analysed data (L4) with the L2P and L3P datasets on which they are based.

Consistent with the collaborative ethos of GHRSST, the generation of the new data products and development of new tools was implemented through a global and regional task-sharing network (Donlon, et al., 2007). Agencies operating at the local or regional level have provided regional data assembly centres (RDAC) in which $L 2 P, L 3 P$ and $L 4$ products are produced. A global data assembly centre (GDAC) was also established at NASA's Jet Propulsion Laboratory, to serve as a repository and distributor of all GHRSST data products, although users can also acquire regionally produced datasets from the appropriate RDACs. After several months, the data products are archived within the GHRSST long-term stewardship and reanalysis facility (LTSRF) hosted at the U.S. National Ocean Data Centre. The production of L2P data for the AATSR was performed by the Medspiration service, the European RDAC, as explained in the next section. 


\section{GHRSST data products and tools delivered by Medspiration}

\subsection{The Medspiration Service}

In 2004 ESA established the Medspiration Project (Robinson, et al., 2005) through its Data User Element (DUE) programme in order to fulfil the role of a European RDAC for GHRSST. The DUE's purpose is to develop new data products and prototype data services in response to a clearly defined need expressed by a significant user community. In the case of the Medspiration project the GHRSST Science Team were considered to represent the worldwide community of operational users of satellite SST data and so the user requirements document which defined the contractual specification of the Medspiration Service was produced by the International GHRSST Project Office. The detailed data processing model that provided the template for software construction was generated following discussions within the GHRSST Science Team (Donlon, 2006). Thus although ESA established the Medspiration project as a regionally based activity, they ensured from the outset that it would conform to standards established by a globally international group of scientists. Moreover, ESA's action in creating the Medspiration project acted as a catalyst prompting GHRSST to establish the first published version (v1.6) of its data processing model.

Initially the functions of the Medspiration processing system were: to generate a geographically limited set of GHRSST-specified combined SST products in near-real time and to serve them to the GDAC and to European operational ocean models; to populate an off-line archive in which to curate the data products; and to provide a data product dissemination service for all types of users. The software contract to construct the system commenced in 2004 and the completed system was accepted by ESA for production use in March 2005. Formally the prototype operational service commenced on 1st June 2005 and delivered data products continuously until December 2008 when its functionality was taken over by a new operational service within 
the Marine Core Service of the European Global Monitoring for Environment and Security (GMES) programme.

The architecture of the Medspiration Service is modular and flexible. There are four independent processing elements, the L2P generator, the MDB, the L4 analyser and the HRDDS, with a data archive at the heart of the system, as illustrated schematically in Figure. 2. The L2P processor continuously polls the suppliers of SST data and as soon as a new data file is found the L2P process is applied to those data. Figure 3 illustrates the image data content of the core elements of a typical Medspiration L2P product, in this case it represents SST produced from the Spinning enhanced visible and infrared imager (SEVIRI) on the geostationary Meteosat $2^{\text {nd }}$ generation platform.

As soon as a new L2P file appears in the archive, the MDB and HR-DDS processors use it to generate their corresponding products. The Medspiration L4 processor operated on a daily cycle, using all the appropriate L2P fields available at a certain cut-off time, as well as the previous analysis, in order to produce a daily, ultra-high resolution SST analysis of the Mediterranean Sea with $2 \mathrm{~km}$ square pixels. The $\mathrm{L} 4$ production system is intended to be robust to variable data supply. For example should one of the sources experience a problem in which no L2 data are delivered for several days, the rest of the system continues to work with other L2 inputs. Although the L4 product quality may suffer from losing an important input, the analysis does the best it can and the end user still gets L4 products when expected. Then when the source comes on-stream again, the backlog of data are processed through the Medspiration system without difficulty. Although the L2P files and their counterpart MDB and HR-DDS files may be delivered too late for the time-critical operational users, they are still available for all other users, and can contribute to subsequent reanalyses and the construction of climate-quality data records. 
The modularity allows the system itself to be distributed across sites or even countries. Whilst the Medspiration project was managed and led at the National Oceanography Centre, Southampton in UK (NOCS), the majority of the L2P processing was initially performed at the Meteo-France Centre for Satellite Meteorology (CMS). The archive, the MDB generator, the AATSR L2P production and the operational control of the whole data system are located at the French Oceanographic Institute, IFREMER in Brest, France, taking advantage of the co-location

there of the Coriolis Service which handles in situ ocean measurements, including the SST records needed for the MDB. IFREMER also hosted the Medspiration L4 analysis system. The HR-DDS is located at NOCS where there is synergy with a programme for validation of AATSR using ship-based radiometry (Wimmer, et al., 2011). The modularity of the system also makes it easy to access L2P data from other RDACs. As long as files are GHRSST-compliant, L2P data can be drawn from elsewhere for use in the L4, MDB and HR-DDS procedures.

\subsection{User-led evolution of the Medspiration Service}

The geographical scope of L2P products was restricted at first to the Atlantic Ocean and European regional seas, this being perceived as the most relevant to European operational ocean forecasting agencies. Thus it was the task of the Medspiration Service to acquire the SST for this geographical zone from the data products listed in Table $2 \mathrm{a}$, and to convert these into L2P products. During the first year of Medspiration's operation, as the GHRSST activities elsewhere in the world developed in parallel with Medspiration, agencies in USA and Japan supplying SST began to generate L2P products themselves, thus eliminating the need for Medspiration to produce its own L2P Atlantic products from those sources.

From the start of the Medspiration project, ESA chose to steer it by regular consultation meetings with a panel of service users, including a number of major operational agencies such as the U.K. Met Office and the Danish Meteorological Institute (DMI), who started to develop experimental L4 products of their own. As a consequence of such consultations, ESA modified 
the evolution of the Medspiration Service. For example, when worldwide operational users of the Medspiration data products made a request to ESA through the GHRSST science team, that European-sourced SST products, in particular the AATSR dual-view SST retrieval, should be made available in $\mathrm{L} 2 \mathrm{P}$ format on a global rather than just a European scale, this was implemented in December 2005. By 2007, the L2P products processed by Medspiration had changed to those shown in Table $2 \mathrm{~b}$. Thus the European RDAC's role had evolved from producing geographically limited L2P data, to producing the L2P version of the full global extent of level 2 SST products generated by European agencies, a pattern adopted by other RDACs around the world. The capacity of the Medspiration system to switch products in and out of the main processing chain in response to changes in the global context, without significant software modifications, demonstrates another benefit of the modular design that had been adopted.

ESA took another strategic decision to extend the operation of the prototype service for three years beyond the single year of demonstration products that was initially specified. This was decided in response to strong advice from institutional operational users who pointed out that extended continuity of data delivery was the most important factor for establishing the confidence they needed to invest in new operational interfaces for using GHRSST products. This provided the stable management environment in which the development of a global operational role for AATSR L2P data products could be nurtured by operational agencies.

\subsection{Medspiration data analysis tools}

The development of the GHRSST approach has reinforced the need to produce individual error statistics for each of the various SST products and also to facilitate the intercomparison of those products in order to characterise their differences. The capacity to perform these functions is especially important if the GHRSST data are to be merged within analysis systems, or assimilated into operational forecasting models. Medspiration provided such functionality by creating the match-up database (MDB) at IFREMER and the high resolution diagnostic dataset 
(HR-DDS) at NOCS. Both of these tools have been instrumental in establishing the accuracy and confirming the stability of the AATSR dual view SST products, and thus contributing to the wider adoption of AATSR data for operational applications.

\subsubsection{Match-up database}

In situ data have proved to be reliable independent sources of SST data for comparing with satellite products as the basis for error statistics. Within the Medspiration project a match-up database (MDB) between satellite and in situ SST data was created at IFREMER. This draws

on the resources of the Coriolis System used for the worldwide collection and archiving of in situ sea temperature and salinity data, (http://www.coriolis.eu.org) which is also based at IFREMER. Using a single source for in situ data ensures that all match-ups are consistent with regard to format, ancillary data content and designated quality levels.

The latest in situ SST data received by Coriolis from drifting and moored buoys are delivered to the Medspiration system on a daily basis. They are collocated with the satellite datasets collected and archived in nearly real time by Medspiration, with a coincidence window of $25 \mathrm{~km}$ in space and 6 hours in time. The retrieved satellite match-ups are then provided back to the Coriolis relational database, linked together with the matching in situ measurements already stored in the database. Doing so ensures that subsequent searches to extract match-up records from the MDB will always find the latest state of the in situ values and quality information. This approach therefore benefits from the most recent delayed-mode quality controls applied by Coriolis to the in situ measurements, including those performed between the ingestion into and the extraction from the database. The coupled Coriolis - MDB system is shown schematically in Figure 4.

The match-up records can be extracted at any time either through a web extraction interface or by downloading periodically generated files of match-up records. Thus the Medspiration MDB provides a unique independent tool for users to check the validity of any given dataset under 
particular conditions (e.g. their area of interest or the time period of their survey). It is being used within GHRSST to monitor the values of single sensor error statistics (SSES - sometimes also called sensor specific error statistics) given by each data provider. The initial providers themselves also make use of it since the Medspiration MDB normally contains data additional to their own more limited match-up databases.

In relation to the wider exploitation of AATSR data, the MDB proved to be essential to enable a review of the SSES assigned to AATSR L2P products. During the early phase of Medspiration data delivery, reports were fed back through user consultations that the Confidence Values (CV) and SSES of the AATSR L2P product were too pessimistic. Users were discarding data labelled as less than the highest quality, which on further inspection appeared to be of better quality than data from other sensors that were flagged as superior quality. A systematic analysis (G. Corlett, Pers. comm.) confirmed that this mainly arose from the use of proximity to cloud as an indicator of suspect quality, whereas the cloud detection for the AATSR level 2 products is extremely reliable. By extensive use of the MDB, a new basis was established for SSES and CVs, using the difference between the dual-view and the nadir-only measures of SST to provide a quality indicator. A detailed explanation of this work is being prepared for publication by $\mathrm{G}$. Corlett and colleagues. The new specification for SSES and CV for AATSR L2P products was adopted in 2007 and has resulted in a much larger proportion of AATSR data being labelled as highest quality $(C V=5)$, further extending the influence of AATSR data in multisensor SST analyses and in assimilation to operational models. Meanwhile, the MDB has been used to develop an experimental, dynamic, continuous bias field for the AATSR data, relative to in situ observations, which avoids the problem of artificial discontinuities arising from the discrete bias values currently specified in the AATSR L2P products (Tandeo, et al., 2009) 


\subsubsection{The High Resolution Diagnostic Dataset}

The purpose of the HR-DDS, proposed by GHRSST and implemented at NOCS, originally as part of the Medspiration Service, is to facilitate intercomparison of the characteristics of the SST derived from different sensor types. The basic concept is simple; over 200 DDS sites are specified, distributed around the world ocean, and typically $2^{\circ}$ lat. $\times 2^{\circ}$ long. in spatial extent. At each of these sites data are extracted from every L2P and L3P data product received at the GDAC containing valid SST pixels over the site, and from all L4 products archived in the GDAC. The extracted data in each granule are resampled by nearest neighbour substitution onto a $0.01^{\circ} \mathrm{grid}$, archived and made publicly available.

Beyond this initial concept established for Medspiration, the HR-DDS has been substantially developed in response to requests from its main users (Poulter and Robinson, 2006). These are the SST producer agencies, who use it for quality control, and the L4 analysers who can use it readily to compare their inputs and outputs. The main development has been the introduction of a web portal to the HR-DDS (www.hrdds.net), which allows users to access pre-evaluated statistical information about every data granule, stored in a relational database. This has further facilitated the comparison between SST data from different sources (including ocean model SST outputs, SST climatologies, other L4 analyses and supporting environmental data including wind speed, solar radiation and sea ice concentration), which is one of the key strengths of the whole GHRSST approach. Data from the HR-DDS are used in section 4 to characterise comparisons between different L2 SST sources and in particular to establish the bias and standard deviation of differences between the SST from AATSR and from other L2P products.

\subsection{Analysis products}

The Medspiration L4 data product is an analysed SST field which is derived from all of the available L2P sources, weighted according to the characteristics and quality of each input value. To generate the L4 product requires that each input L2P value should first be converted to the 
foundation SST by estimating the magnitude of any diurnal warm layer and, in the case of infrared data, the cool skin effect. This is facilitated by the availability of the ancillary data within the L2P product. However, until we have sufficient confidence in models that estimate diurnal warming, the ancillary data are used instead to identify and reject altogether data with a high probability of being affected by a diurnal thermocline (i.e. daytime low wind situations). Then an optimal interpolation scheme is applied to merge the data from different sources and to fill gaps resulting from cloud or other causes of data dropout. This makes use of the error estimates contained in the L2P products. The resulting L4 product, evaluated daily, corresponds to the foundation SST. Since its initiation, Medspiration produced L4 data on a $2 \times 2 \mathrm{~km}$ grid for the Mediterranean Sea. Following requests from the European Marcoast project as a key user of satellite products, a second L4 $2 \mathrm{~km}$ analysis was introduced in 2006, covering the N.W. European Shelf Sea area. In 2007, a further analysis over the Galapagos region in the Eastern Equatorial Pacific was also developed in direct response to user needs. The basic analysis method in each case is that developed at Ifremer (Autret and Piollé, 2007). Examples of Medspiration L4 SST products from each of these regions on randomly selected dates are shown in Figs 5, 6 and 7 respectively. These analyses reveal much of the high resolution dynamic structure that is expected in these regions, including the Alboran Gyre (Fig. 5), the Irish Sea tidal mixing fronts (Figure 6) and the Tehuantepec upwelling (Figure 7) although other features are less readily interpreted, such as the anomalously cool waters surrounding Scotland in figure 6. There is evidently a need to systematically assess these new high resolution analyses to determine whether artefacts are created in the thermal patterns by the spatial structures of the recent sampling history.

One of the main challenges in blending multi-sensor data is to cope with the discrepancies between the different observations. The factors causing the biases observed between different sensors and different overpasses of the same sensor include: different sampling time, different 
sampling resolution, bad cloud screening, aerosol contamination (affecting the available sensors unequally), no intercalibration of the various sensors, and others. The benefit of the L2P file format is to provide the ancillary information required to build up a filtering and selection strategy where several simultaneous observations are available. In addition to that, the match-up database is used as a basis to improve the sensor bias estimation, depending on their confidence values, which should be uniquely related to known weaknesses in particular sensors and in the original L2 data processing chain. Medspiration, by providing a coherent set of tools and data, has therefore made it much easier to develop improved high level products.

The L4 analysis element in Medspiration was not intended to provide a comprehensive service to all European users but to serve as a demonstrator of what is possible using the ready access to all SST data sources provided by the L2P products. Since the start of Medspiration several other analysis datasets have been developed by different agencies in Europe, and these are discussed in section 5 since they represent an important route by which AATSR data is influencing operational applications of SST. Where such datasets conform to the GHRSST specification they are recognised as GHRSST products and can be deposited at the GDAC where the Medspiration L4 products are also sent. In this way, a healthy mix of co-operation and competition is encouraged in the L4 analysis sector, where there is scope for steady improvement in the methods of optimal interpolation and objective analysis, and where there is also a need to match particular configurations of the analyses methods to specific application requirements. 


\section{Understanding the characteristics of SST data products}

From June 2005 when the Medspiration Service started delivering products as a prototype operational service, it soon became apparent that it was opening up new opportunities to explore the character of satellite-derived SST in general. This section identifies some scientific insights about the variability of measured SST that were not previously apparent. The population of the SST diagnostic dataset, which itself is dependent on the production of GHRSST L2P and L4 data products, has facilitated intercomparison of data from different sources. Whilst a somewhat worrying picture emerges of considerable differences between almost coincident measurements, such information is essential for effective analysis of the combined data. In fact it provides an opportunity to use the AATSR as a common reference against which other sources of data can be bias-adjusted. Without the establishment of the Medspiration service, it would not have been possible to develop these new insights since the appropriate data would not have been available.

\subsection{Comparison between coincident SST Observations}

Figure 8 shows time series of every satellite SST measurement averaged over the pixels of a $2^{\circ} \times 2^{\circ}$ DDS site in the central North Atlantic for a period of 10 days. This is typical of many such DDS plots, illustrating the magnitude of the variations between observations made within the same area and at almost the same time by different sensors. The spread of up to $2 \mathrm{~K}$ between measurements on the same day can partly be associated with the character of the SST field. For example the data from a geostationary orbit sampled every 3 hrs (red dots) show the strength of the diurnal warming / cooling cycle on some days. In both night and day a difference is expected between MW and IR observations, but the size of this skin effect is typically no more than about $0.15 \mathrm{~K}$ (Donlon, et al., 2002). Variability is also expected because the position of cloud within the full DDS site may shift between the overpases of different satellites. The other main cause of the temperature spread across coincident SST retrievals from different sensors 
must be attributed to errors in each of the measurement systems. These may be errors in the calibration of sensor detectors, inadequate correction for atmospheric effects or shortcomings in the end-to-end SST retrieval method.

The discrepancies between different samples of SST present an obstacle to the simple merging of observations from diverse sources of satellite data. Interpolation techniques must be able to cope with random errors, but if there are systematic biases between different sources these should be removed before trying to combine the data. The HR-DDS allows us to explore the differences between the SST from different systems. Figure 9 shows an example of the yearlong average of the bias and standard deviation of differences between SST as measured by the Advanced Scanning Microwave Radiometer (AMSR-E) and AATSR, and SEVIRI and AATSR. These reveal substantial biases of order $1 \mathrm{~K}$. Note that these figures relate to the SEVIRI and AMSR-E products as produced in 2007, and may not apply to current retrieval algorithms for those sensors. In fact the availability of the HR-DDS comparisons is one of the factors used by some agencies when making decisions to revise their SST retrieval algorithms. It is interesting to see in the SEVIRI data a definite geographical pattern to the bias distribution. A small positive bias in most regions becomes a larger negative bias across the tropical $\mathrm{N}$. Atlantic and the Persian gulf, where Saharan dust sometimes creates problems for the atmospheric correction. The dual view of the AATSR is better able to correct for the apparent cooling effect of Saharan dust, as confirmed by the absence of the same pattern in the AATSR difference from AMSR-E which, being a microwave radiometer, should not be affected by this problem. By facilitating routine comparisons between SEVIRI and AATSR data, the Medspiration L2P data products helped to bring to light the SEVIRI algorithm problem with dust, prompting action to remedy it by establishing a Saharan dust index (SDI) (Merchant, et al., 2006). It has recently been shown (Marullo, et al., 2010) that the observed difference between 
SEVIRI and AATSR is not only due to dust, but is also associated with a more complex seasonal algorithm bias, also evidenced in relation to the SST retrieved from AMSR-E.

\subsection{Bias Adjustment before SST Analyses}

Before data from different sources can be merged or blended in an optimal interpolation analysis, or assimilated into an ocean forecasting model, it is important to remove the difference in biases between different datasets. This can be done by comparing each of them to the same reference dataset, which hitherto has generally been a set of in situ observations, although because daily matches between satellite and in situ datasets are sparse the resulting bias fields tend to be smoothed over large length and timescales. An alternative approach is to compare directly the coincident SST data fields from different satellite sensors, yielding many more matches each day. The resulting bias fields between pairs of SST products are better able to characterise the spatial and temporal variability of the differences between the SST datasets.

If one of the satellite datasets is chosen as a common reference, all the others can be adjusted to remove their bias relative to it. The resulting analysed SST field should contain less spatial patchiness caused by the overlapping of differently biased datasets. This satisfies the requirement of near real-time operational applications for reliable knowledge of SST gradients and the continually changing spatial patterns of isotherms. However it should be noted that it does not provide an absolute reference for the resulting level 4 SST field, unless the common reference dataset has itself been independently validated by reference to in situ observations (such as in Tandeo, et al., 2009).

The repackaging by the Medspiration Service of global AATSR data into the GHRSST L2P format, along with similar repackaging of other data sources and their ready availability through the GHRSST GDAC, has greatly simplified the task of comparing different satellite datasets. The products from the Medspiration service enabled several user groups (Donlon, et al., 2011; Le Borgne, et al., 2011) to develop SST analysis products which use this bias adjustment 
approach with AATSR data as the reference dataset. AATSR dual-view data are potentially attractive as the common reference because they are designed to minimise bias and sensitivity to atmospheric aerosols (Merchant and Harris, 1999; Merchant, et al., 1999), they have been validated globally against buoy data (O'Carroll, et al., 2006; O'Carroll, et al., 2008) and their stability over six years has been demonstrated in a limited geographical region by comparison with ship-board infra red radiometry (Wimmer, et al., 2011).

In principle these characteristics should make AATSR the first choice source of measurements for an SST analysis or assimilation scheme. Unfortunately the dual view which provides the reliable accuracy also limits the swath width so the AATSR has quite poor coverage (see Fig. 1). Figure 10 illustrates this where the narrow purple stripe is the only coverage from one day's AATSR data, whereas most of the area is included in AVHRR Global Area Coverage or SEVIRI data. For ten years this tended to deter potential operational users from considering the ATSR and ATSR-2 products, the predecessors to AATSR. Although the AATSR coverage is sparse when used by itself for mapping, it is evident from Fig. 10 that there is quite a lot of overlap with the other datasets that have wider coverage.

In the example shown in Figure 11, a new analysis method developed by CMS (Le Borgne, et al., 2006) produces spatially variable biases for SEVIRI and AVHRR based on matches with AATSR over a five day period. The image in Figure 11a shows the effect of simply collating the available data ready for optimal interpolation, placing data from AATSR as first preference, then filling in the gaps successively with AVHRR and then SEVIRI. Without adjustment, the different biases of the three sources of data project onto the collated image as discontinuities along the boundaries between data sources. Such sharp edges are bound to corrupt the final analysis. In Figure $11 \mathrm{~b}$ the bias adjustment to AATSR has been applied. Not only have the sharp edges disappeared but also the temperature has been raised significantly in those regions where the SEVIRI data were too cold. The result is a more reliable representation of the spatial gradients 
of SST, important for high resolution NWP, although the absolute SST accuracy depends on that of AATSR in the region. Further research has continued to optimise the choice of the time window and the averaging length scale when calculating the bias (Le Borgne, et al., 2011). 


\section{Growth in operational use of SST in response to Medspiration}

In response to the increasing demand for accurate high-resolution SST the UK Met Office developed a new operational Sea Surface Temperature and Sea Ice analysis (OSTIA) system as a UK contribution to GHRSST (Donlon, et al., 2011). In OSTIA the bias adjustment reference dataset contains in situ observations augmented with AATSR data. In this way far more data are available each day for reference and the coverage is extended into regions where there are few if any buoy or ship measurements. This has proved to be particularly important for determining the spatial structure of the AMSR-E biases in the Southern and Arctic oceans.

In Australia, the Bureau of Meteorology's BlueLink project uses AATSR SST data to tune the parameters in empirical algorithms for local atmospheric correction of AVHRR data. The outcome is regional maps of SST that are already bias corrected to AATSR and which should enjoy the same improved stability as AATSR.

Figure 12 is a global SST map from another real-time global analysis developed within the MERSEA programme by IFREMER (Autret and Piollé, 2007). It merges all available SST sensors after first using AATSR as a reference sensor to correct the large-scale bias of all other sensors. However the AATSR data are first adjusted using a statistical correction model built from the match-up database (Tandeo, et al., 2009). This new processing scheme was also applied from early 2008 to the high-resolution regional L4 products of Medspiration mentioned in section 3.4. The MERSEA global analysis offers an alternative to the OSTIA product. Redundancy of this kind is to be encouraged. Any divergence between the two analyses serves to remind users of the fallibility of the analysis process and its sensitivity to the particular configuration adopted for the optimal interpolation scheme. Users concerned with climate monitoring will welcome the availability of several different analyses since they can use an ensemble of all the available analyses to gain a statistical measure of uncertainty from the 
differences. In fact there are now more than ten global SST analyses being produced in L4 format by different agencies worldwide, and GHRSST has established a facility on line to present these publicly as the GHRSST Multi-Product Ensemble (GMPE).

The Medspiration Service, having served its purpose as a demonstration of a European RDAC for GHRSST handed over its functionality in 2009 to a new operational SST Thematic Assembly Centre (SST-TAC) within an entity called MyOcean which is contracted by the European Union to deliver the Marine Core Service as an element within the European Global Monitoring for Environment and Security (GMES) initiative. The L2P processing operations pioneered in Medspiration have now been taken over by the European agencies which produce the level 2 products, including a new data stream from the AVHRR on the METOP satellite. These agencies are Eumetsat (through its Ocean and Sea Ice Satellite Application Facility-OSISAF) and ESA. The SST-TAC now continues to maintain the HR-DDS at NOCS, the MDB at IFREMER, co-ordination of the data flow, archiving, linking to the GDAC and distributing to users, as well as producing a global and a regional L4 product. 


\section{Conclusion}

Since it started to deliver data regularly in June 2005, the Medspiration Service proved the effectiveness of the strategic concepts and data processing model developed by GHRSST for combining SST data from many sources. The modular approach of GHRSST, based on common formats and specifications agreed by producers, users and scientists, has allowed the new generation of products to move rapidly from planning to production. Now that data from different sources are being used together and intercompared, it is evident that each different SST system has a particular role to play. The benefit of the resulting cooperation, in contrast to a narrow competitiveness which discourages redundancy of observations, is that the resulting new analysis products appear to be of higher quality than ever before, in terms of accuracy, resolution, speed of delivery and effectiveness in operational applications.

In this respect, the Medspiration project serves as an excellent demonstration of the effectiveness of the approach that the Global Earth Observing System of Systems (GEOSS) is seeking to promote across the breadth of Earth Observation. By setting out the detailed processing specification for global SST data delivery, and then encouraging regional players to take the initiative, GHRSST created the fertile environment in which the Medspiration project could thrive, given the support of the European Space Agency. Medspiration's success is also being matched by regional activities in other continents. The consequence is that oceanographers and meteorologists around the world stand to benefit from improved SST data for real time applications and for climate monitoring

It is also evident that by making AATSR data available in the standard GHRSST L2P format, the Medspiration Service has opened up the benefits of the AATSR's high quality data to a greater number of users around the world. Without access to the more stable AATSR data, the L4 products facilitated by the GHRSST strategy would struggle to find a stable way to remove the biases between the different L2P inputs, especially when conditions of atmospheric dust 
degrade the retrievals from single-view infrared sensors. Once this special role for AATSR L2P data in operational SST applications had been recognised, ocean and weather forecasting agencies around the world voiced the importance of maintaining long term continuity of an AATSR class sensor. For this reason the SST sensor (Sea and land surface temperature radiometer - SLSTR) planned for the Sentinel-3 series of ESA satellites, intended to support the GMES marine cores services, will have a specification comparable to that of AATSR (Aguirre, et al., 2007).

The contribution of AATSR's quality to more reliable analyses of SST is not only leading to more accurate climate datasets, which was the goal of the first ATSR sensor in 1991, but has already led to improved weather forecasts, and the assimilation of SST into ocean forecasting models. These benefits were not foreseen when the ATSR series was first developed. They have arisen because of the co-operative framework for international collaboration that has emerged from the satellite SST community in response to the GHRSST initiative, as demonstrated by the Medspiration Service. It is now important that momentum is maintained for further improvement in operational SST products, not only by ensuring that the SLSTR exceeds the quality of AATSR, but also by maintaining the quality and continuity of the other sensor classes outlined in Table 1. 


\section{Acknowledgements}

During the first phase of the Medspiration project a number of other colleagues made significant contributions to the design and implementation of the Medspiration system. These include: Lia Santoleri and Bruno Buongiorno-Nardelli of CNR, Rome; Steinar Eastwood of MetNo, Sylvie Pouliquen, Jean Tournadre and Romain de Joux of Ifremer, Alain Coat and Sophie Casitas of Actimar, Brest; James Rickards and Gareth Davies of Vega UK plc; and Simon Ruiz and Gilles Larnicol of CLS.

The authors also wish to acknowledge the valuable contributions to the development of the work described in this paper from other members of the GHRSST-PP Science Team, and from participants in the Medspiration User Consultation Meetings. Special thanks go to Edward Armstrong and Jorgé Vazquez of JPL who manage the GDAC through which many of the Medspiration products reach worldwide users.

Thanks are also owed to the anonymous referees for pointing out the need for some critical clarifications.

\section{REFERENCES}

Aguirre, M., B. Berruti, J.-L. Bezy, M. Drinkwater, F. Heliere, U. Klein, C. Mavrocordatos, P. Silvestrin, B. Greco and J. Benveniste (2007) Sentinel-3: Th e ocean and medium-resolution land mission for GMES operational services, ESA Bulletin, 131, (August 2007), 24-29.

Autret, E. and J.-F. Piollé (2007) Implementation of a global SST analysis., MERSEA IP (Marine EnviRonment and Security for the European Area - Integrated Project), MERSEA-WP02-IFR-STR-001-1A.doc., 28 pp, IFREMER, Brest, Available through http://www.mersea.eu.org/.

Bell, M. J., R. M. Forbes and A. Hines (2000) Assessment of the FOAM global data assimilation system for realtime operational ocean forecasting, J. Mar. Syst., 25, 1-22.

Chelton, D. B., M. G. Schlax and R. M. Samelson (2007) Summertime Coupling between Sea Surface Temperature and Wind Stress in the California Current System, J. Phys. Oceanog, 37, 495-517, doi: 10.1175/JPO3025.1.

Chelton, D. B. and F. J. Wentz (2005) Global Microwave Satellite Observations of Sea Surface Temperature for Numerical Weather Prediction and Climate Research, Bull. Am. Meteorol. Soc., 86, 1097-1115, doi: 10.1175/BAMS-86-8-1097.

Corlett, G. K., I. J. Barton, C. J. Donlon, M. C. Edwards, S. A. Good, L. A. Horrocks, D. T. Llewellyn-Jones, C. J. Merchant, P. J. Minnett, T. J. Nightingale, E. J. Noyes, A. G. O’Carroll, J. J. Remedios, I. S. Robinson, R. W. Saunders and J. G. Watts (2006) The accuracy of SST retrievals from AATSR: an initial assessment 
through geophysical validation against in situ radiometers, buoys and other SST data sets, Adv. Space Res., 37, (4), 764-769.

Donlon, C. J. (Ed.) (2006) The GHRSST-PP Data processing Specification version 1.6, GHRSST International Project Office, http://www.ghrsst.org.

Donlon, C. J., M. Martin, J. Stark, J. Roberts-Jones, E. Fiedler and W. Wimmer (2011) The operational Sea Surface Temperature and Sea ice Analysis (OSTIA) system, Remote Sensing of Environment, doi: 10.1016/j.rse.2010.10.017.

Donlon, C. J., P. J. Minnett, C. Gentemann, T. J. Nightingale, I. J. Barton, B. Ward and M. J. Murray (2002) Towards improved validation of satellite sea surface skin temperature measurements for climate research, J. Climate, 15, (4), 353-369.

Donlon, C. J., I. S. Robinson, K. S. Casey, J. Vazquez, E. Armstrong, O. Arino, C. L. Gentemann, D. May, P. Le Borgne, J.-F. Piollé, I. Barton, H. Beggs, D. J. S. Poulter, C. J. Merchant, A. Bingham, S. Heinz, A. Harris, G. Wick, W. J. Emery, P. Minnett, R. Evans, D. T. Llewellyn-Jones, C. T. Mutlow, R. Reynolds, H. Kawamura and N. Rayner (2007) The Global Ocean Data Assimilation Experiment (GODAE) High Resolution Sea Surface Temperature Pilot Project (GHRSST-PP), Bull. Am. Meteorol. Soc., 88, (8), 1197 1213, doi: 10.1175/BAMS-88-8-1197.

Edwards, T., R. Browning, J. Delderfield, D. J. Lee, K. A. Lidiard, R. S. Milborrow, P. H. McPherson, S. C. Peskett, G. M. Toplis, H. S. Taylor, I. Mason, G. Mason, A. Smith and S. S. (1990) The Along Track Scanning Radiometer measurement of sea-surface temperature from ERS-1, J. British Interplanetary Soc. , 43, 160180.

Johannessen, J. A., P.-Y. L. Traon, I. S. Robinson, K. Nittis, M. J. Bell, N. Pinardi and P. Bahurel (2006) Marine environment and security for the European area: Toward Operational Oceanography, Bull. Am. Meteorol. Soc., 87, (8), 1081-1090.

Le Borgne, P., A. Marsouin, F. Orain and H. Roquet (2011) Operational sea surface temperature bias adjustment using AATSR data, Remote Sens. Environ., this issue.

Le Borgne, P., A. Marsouin, F. Orain, H. Roquet, A. Coat and Y. Guichoux (2006) Implementation of a fine scale SST analysis over the Atlantic Ocean, MERSEA document MERSEA-WP02-MF-STR-002-1A (Available from www.mersea.eu.org), $30 \mathrm{pp}$

Marullo, S., R. Santolieri, V. Banzon, R. H. Evans and M. Guarracino (2010) A diurnal-cycle resolving sea surface temperature product for the tropical Atlantic, J. Geophys. Res., 115, (C05011), doi: 10.1029/2009JC005466.

Merchant, C. J., O. Embury, P. Le Borgne and B. Bellec (2006) Saharan dust in nighttime thermal imagery: Detection and reduction of related biases in retrieved sea surface temperature., Remote Sens. Environ., 104, $15-30$.

Merchant, C. J., M. J. Filipiak, P. Le Borgne, H. Roquet, E. Autret, J.-F. Piollé and S. Lavender (2008a) Diurnal warm-layer events in the western Mediterranean and European shelf seas, Geophys. Res. Lett., 35, (L04601), doi: 10.1029/2007GL033071.

Merchant, C. J. and A. R. Harris (1999) Toward the elimination of bias in satellite retrievals of sea surface temperature 2. Comparison with in situ measurements, J. Geophys. Res., 104, (C10), 23579-23590.

Merchant, C. J., A. R. Harris, M. J. Murray and A. M. Závody (1999) Toward the elimination of bias in satellite retrievals of sea surface temperature 1. Theory, modelling and interalgorithm comparison., J. Geophys. Res., 104, (C10), 23565-23578.

Merchant, C. J., D. T. Llewellyn-Jones, R. W. Saunders, N. Rayner, E. C. Kent, C. P. Old, D. Berry, A. R. Birks, T. Blackmore, G. K. Corlett, O. Embury, V. L. Jay, J. Kennedy, C. T. Mutlow, T. J. Nightingale, A. G. O'Carroll, M. J. Pritchard, J. J. Remedios and S. Tett (2008b) Deriving a sea surface temperature record suitable for climate change research from the along-track scanning radiometers, Adv. Space Res., 41, 1-11.

Murray, M. J., M. R. Allen, C. T. Mutlow, A. M. Zavody, M. S. Jones and T. N. Forrester (1998) Actual and potential information in dual-view radiometric observations of sea surface temperature from ATSR, $J$. Geophys. Res., 103, (C4), 8153-8165.

Noyes, E. J., P. J. Minnett, J. J. Remedios, G. K. Corlett, S. A. Good and D. T. Llewellyn-Jones (2006) The accuracy of the AATSR sea surface temperatures in the Caribbean, Remote Sens. Environ., 101, (1), 38-51.

O'Carroll, A. G., J. R. Eyre and R. W. Saunders (2008) Three-way error analysis between AATSR, AMSR-E, and in situ sea surface temperature observations, J. Atmos. Oceanic Technology, 25, 1197-1207.

O'Carroll, A. G., J. G. Watts, L. A. Horrocks, R. W. Saunders and N. A. Rayner (2006) Validation of the AATSR meteo product sea surface temperature, J. Atmos. Ocean. Technol., 23, (5), 711-726. 
Parkes, I. M., T. N. Sheasby, D. T. Llewellyn-Jones, T. J. Nightingale, A. M. Závody, C. T. Mutlow, R. Yokoyama, S. Tamba and C. J. Donlon (2000) The Mutsu Bay Experiment: Validation of ATSR-1 and ATSR-2 sea surface temperature, Int. J. Remote Sensing., 21, (18), 3445-3460.

Poulter, D. J. S. and I. S. Robinson (2006) Diagnostic tools applicable to MERSEA SST products: The NOCS High Resolution Diagnostic Data Set (HR-DDS) System, MERSEA IP (Marine EnviRonment and Security for the European Area - Integrated Project), MERSEA Deliverable 2.2.3revB.doc, IFREMER, Brest, available through http://www.mersea.eu.org/.

Reynolds, R. W., N. A. Rayner, T. M. Smith, D. C. Stokes and W. Wang (2002) An improved in situ and satellite SST analysis for climate, J. Climate, 15, 1609-1625.

Robinson, I. S. and C. J. Donlon (2003) Global Measurement of Sea Surface Temperature from Space: Some New Perspectives, J. Atm. Ocean Sci. (previously The Global Atmosphere and Ocean System), 9, (1), 19-37.

Robinson, I. S., J.-F. Piollé, P. Le Borgne, C. J. Donlon and O. Arino (2005), MEDSPIRATION : A European Contribution to the Global Ocean Data Assimilation Experiment High Resolution Sea Surface Temperature Pilot Project, In, Proc. MERIS-AATSR Workshop, ESRIN, September 2005, European Space Agency.

Smith, N. R. and C. Koblinsky (2001) The ocean observing system for the 21st Century, a consensus statement, In Koblinsky, C. and N. R. Smith (Eds.) Observing the Oceans in the 21st Century, GODAE Project Office, Bureau of Meteorology, Melbourne, Australia,, pp. 1-25.

Stuart-Menteth, A. R., I. S. Robinson and C. J. Donlon (2005) Sensitivity of the diurnal warm layer to meteorological fluctuations. Part 2: A new parameterisation for diurnal warming, J. Atm. Ocean Sci. (previously The Global Atmosphere and Ocean System), 10, (3), 209-234.

Tandeo, P., E. Autret, J. F. Piollé, J. Tournadre and P. Ailliot (2009) A multivariate regression approach to adjust AATSR sea surface temperature to in situ measurements, I.E.E.E. Geoscience and Remote Sensing Letters, 6, (1), 8-12.

Wimmer, W., I. S. Robinson and C. J. Donlon (2011) Long-term Validation of AATSR SST data products using shipborne radiometry in the Bay of Biscay and English Channel, Remote Sens. Environ., doi: 10.1016/j.rse.2011.03.022.

Závody, A. M., C. T. Mutlow and D. T. Llewellyn-Jones (1995) A radiative transfer model for sea surface temperature retrieval for the along-track scanning radiometer., J. Geophys. Res., 100, 937-952. 
Table 1. Minimum assemblage of missions required to meet the need for operational SST.

\begin{tabular}{|c|c|c|c|c|c|}
\hline & SST mission type & Radiometer wavebands & $\begin{array}{l}\text { Nadir } \\
\text { resolution }\end{array}$ & $\begin{array}{l}\text { Swath width } \\
\text { (approx.) }\end{array}$ & Coverage / revisit \\
\hline A & $\begin{array}{l}\text { Two polar orbiting meteorological } \\
\text { satellites with infra-red radiometers, in } \\
\text { complementary orbits. }\end{array}$ & $\begin{array}{c}3 \text { thermal IR }(3.7,11,12 \\
\mu \mathrm{m}) 1 \text { near-IR, } 1 \text { Vis }\end{array}$ & $1.1 \mathrm{~km}$ & $2500 \mathrm{~km}$ & $\begin{array}{l}\text { Day and night } \\
\text { global coverage by } \\
\text { each satellite }\end{array}$ \\
\hline B & $\begin{array}{l}\text { Polar orbiting microwave radiometer } \\
\text { optimised for SST retrieval }\end{array}$ & $\begin{array}{l}\text { Requires channels at } \sim 7 \\
\quad \text { and } \sim 11 \mathrm{GHz}\end{array}$ & $\begin{array}{l}\sim 50 \mathrm{~km}(25 \\
\mathrm{km} \text { pixels })\end{array}$ & $1500 \mathrm{~km}$ & $\begin{array}{c}\text { Earth coverage in } 2 \\
\text { days }\end{array}$ \\
\hline $\mathrm{C}$ & $\begin{array}{l}\text { Infra-red radiometers on geostationary } \\
\text { platforms, at fixed longitude. }\end{array}$ & $\begin{array}{l}3 \text { thermal IR }(3.7,11,12 \\
\mu \mathrm{m}) 1 \text { near-IR, } 1 \text { Vis }\end{array}$ & $2-4 \mathrm{~km}$ & $\begin{array}{l}\text { Earth disk } \\
\text { from } 36000 \\
\mathrm{~km} \text { altitude }\end{array}$ & $\begin{array}{l}\text { Sample interval }< \\
30 \mathrm{~min}\end{array}$ \\
\hline $\mathrm{D}$ & $\begin{array}{l}\text { Polar orbiting dual-view radiometer. SST } \\
\text { accuracy approaching } 0.1 \mathrm{~K} \text {, used as } \\
\text { reference standard for other types. }\end{array}$ & $\begin{array}{l}3 \text { thermal IR }(3.7,11,12 \\
\mu \mathrm{m}) 1 \text { near-IR, } 1 \text { vis, each } \\
\text { with dual view }\end{array}$ & $1 \mathrm{~km}$ & $500 \mathrm{~km}$ & $\begin{array}{c}\text { Earth coverage in } \\
\sim 4 \text { days }\end{array}$ \\
\hline
\end{tabular}

Table 2. SST L2P data products generated by the Medspiration Service, (a) At the initiation of the service in 2005. (b) Following a rationalisation of the Medspiration Service in May 2007 by which time L2P products of NOAA and AMSR-E data were being produced in the U.S.A. by the MISST (Multi-sensor Improved Sea Surface Temperature for GODAE) project.

\begin{tabular}{|c|c|c|c|c|c|}
\hline Product & Satellite/Sensor & Source provider & Resolution & Spatial coverage & $\begin{array}{l}\text { Production } \\
\text { rate }\end{array}$ \\
\hline \multicolumn{5}{|c|}{ (a) Situation at initiation of Service in 2005} & Files/day \\
\hline ATS_NR_2P & ENVISAT / AATSR & European Space Agency & $1 \mathrm{~km}$ & $\begin{array}{l}\text { Atlantic (including } \\
\text { Mediterranean) }\end{array}$ & $14-15$ \\
\hline $\begin{array}{l}\text { AVHRR16_G } \\
\text { AVHRR17_G }\end{array}$ & $\begin{array}{l}\text { NOAA16 / AVHRR } \\
\text { NOAA17 / AVHRR }\end{array}$ & $\begin{array}{l}\text { NASA / JPL Physical } \\
\text { Oceanography Distributed Active } \\
\text { Archive Centre (PO.DAAC) }\end{array}$ & $9 \mathrm{~km}$ & $\begin{array}{l}\text { Atlantic (including } \\
\text { Mediterranean) }\end{array}$ & $\begin{array}{l}14 \\
14\end{array}$ \\
\hline $\begin{array}{l}\text { AVHRR16_L } \\
\text { AVHRR17_L }\end{array}$ & $\begin{array}{l}\text { NOAA16 / AVHRR } \\
\text { NOAA17 / AVHRR }\end{array}$ & NASA / JPL PO.DAAC & $1-2 \mathrm{~km}$ & $\begin{array}{c}\text { Eastern } \\
\text { Mediterranean }\end{array}$ & $\begin{array}{l}4-5 \\
4-5\end{array}$ \\
\hline $\begin{array}{l}\text { NAR16_SST } \\
\text { NAR17_SST } \\
\text { NAR18_SST }\end{array}$ & $\begin{array}{l}\text { NOAA16 / AVHRR } \\
\text { NOAA17 / AVHRR } \\
\text { NOAA18 / AVHRR }\end{array}$ & $\begin{array}{l}\text { Eumetsat Oceans \& Sea Ice } \\
\text { Satellite Applications Facility } \\
\text { (OSI SAF) }\end{array}$ & $1-2 \mathrm{~km}$ & $\begin{array}{l}\text { European Shelf Seas } \\
\& \text { Mediterranean }\end{array}$ & $\begin{array}{l}2 \\
2 \\
2\end{array}$ \\
\hline SEVIRI_SST & MSG / SEVIRI & Eumetsat OSI SAF & $10 \mathrm{~km}$ & $\begin{array}{l}\text { Atlantic (including } \\
\text { Mediterranean) }\end{array}$ & 8 \\
\hline AMSRE SST & AQUA / AMSRE & $\begin{array}{l}\text { Remote Sensing Systems Inc. } \\
\text { (REMSS) }\end{array}$ & $25 \mathrm{~km}$ & $\begin{array}{l}\text { Atlantic (including } \\
\text { Mediterranean) }\end{array}$ & $8-9$ \\
\hline TMI SST & TRMM / TMI & REMSS & $25 \mathrm{~km}$ & $\begin{array}{l}\text { Atlantic (including } \\
\text { Mediterranean }\end{array}$ & $9-10$ \\
\hline \multicolumn{6}{|c|}{ (b) Situation in May 2007} \\
\hline ATS_NR_2P & ENVISAT / AATSR & European Space Agency & $1 \mathrm{~km}$ & Global & $14-15$ \\
\hline $\begin{array}{l}\text { NAR17_SST } \\
\text { NAR18_SST }\end{array}$ & $\begin{array}{l}\text { NOAA17 / AVHRR } \\
\text { NOAA18 / AVHRR }\end{array}$ & $\begin{array}{l}\text { Eumetsat Oceans \& Sea Ice } \\
\text { Satellite Applications Facility } \\
\text { (OSI SAF) }\end{array}$ & $1-2 \mathrm{~km}$ & $\begin{array}{l}\text { N. Atlantic (inc. } \\
\text { Mediterranean) }\end{array}$ & $\begin{array}{l}2 \\
2 \\
2\end{array}$ \\
\hline SEVIRI_SST & MSG / SEVIRI & Eumetsat O\&SI SAF & $10 \mathrm{~km}$ & Full Earth disc & 8 \\
\hline
\end{tabular}



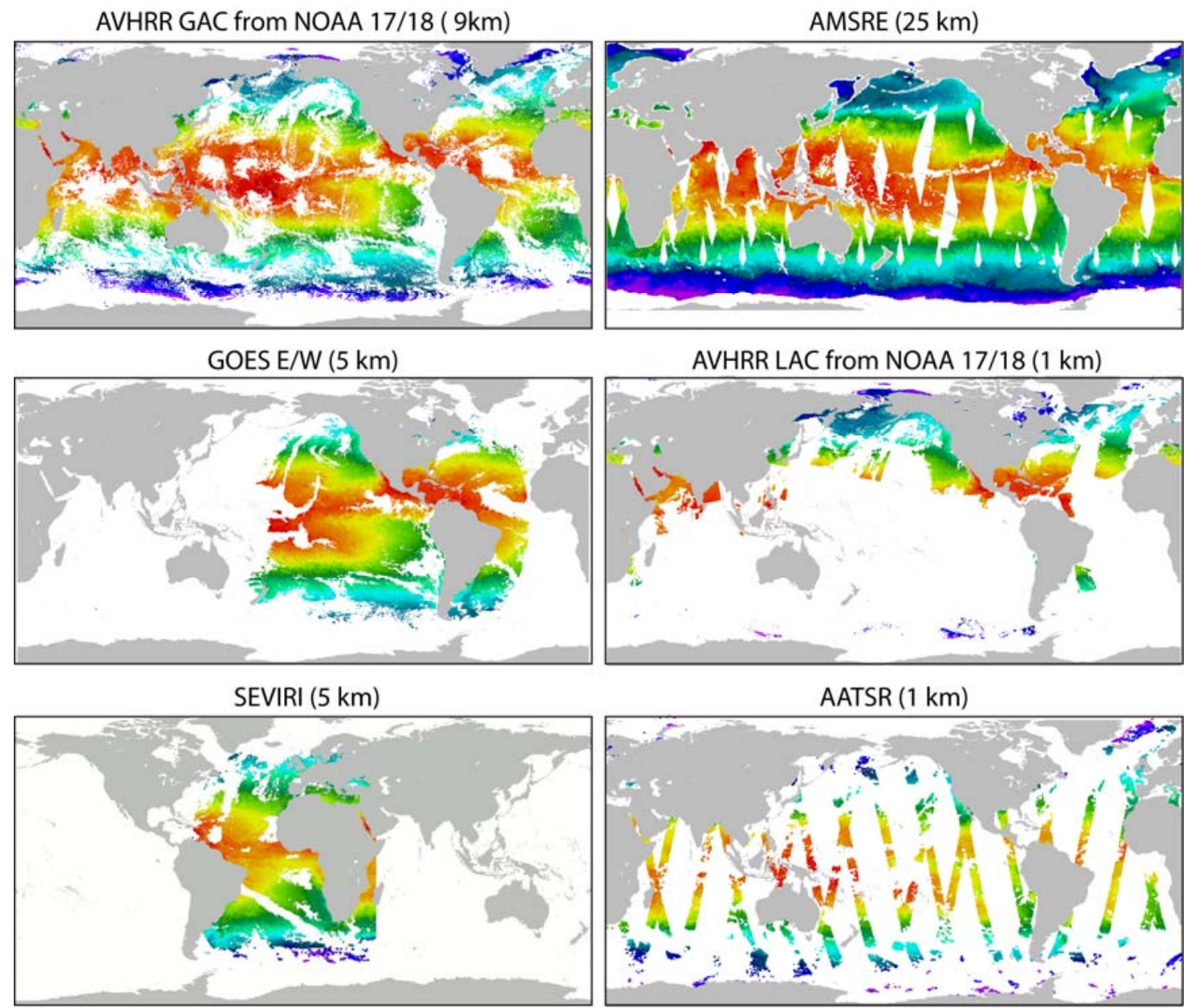

Figure 1. Typical example of the daily coverage of SST from six different SST data products, at different spatial resolutions, all from the same day.

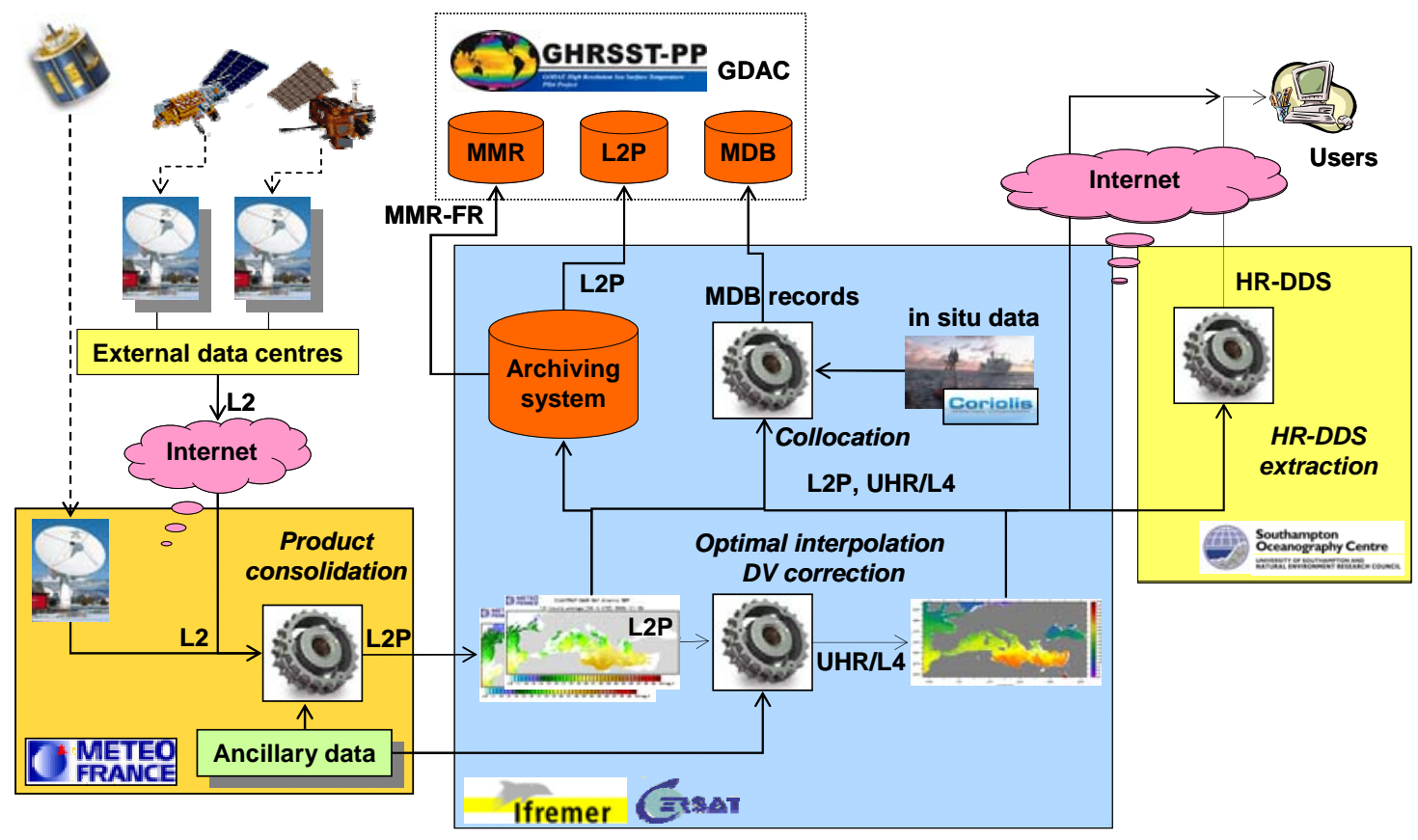

Figure 2. Schematic of the Medspiration processing chain 


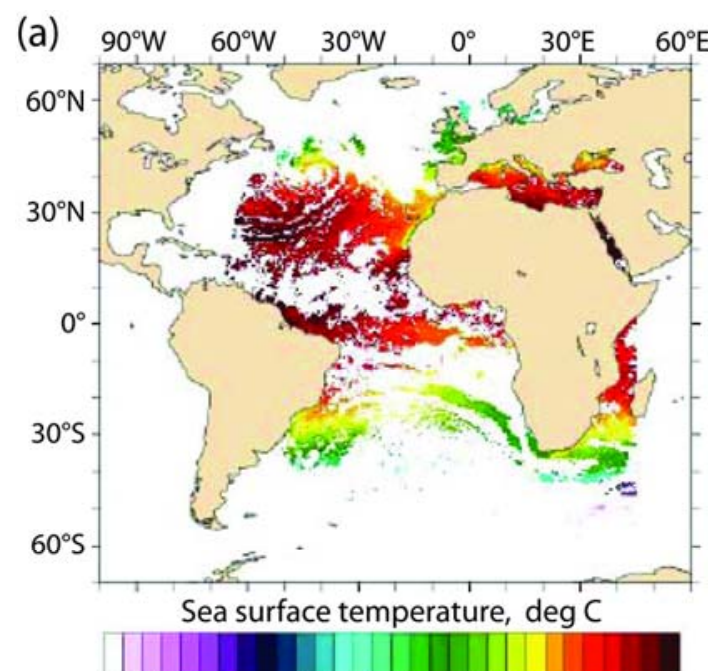

$\begin{array}{llllllll} & 0 & 5 & 10 & 15 & 20 & 25 & \\ \text { (c) } \quad 90^{\circ} \mathrm{W} & 60^{\circ} \mathrm{W} & 30^{\circ} \mathrm{W} & 0^{\circ} & 30^{\circ} \mathrm{E} & 60^{\circ} \mathrm{E}\end{array}$

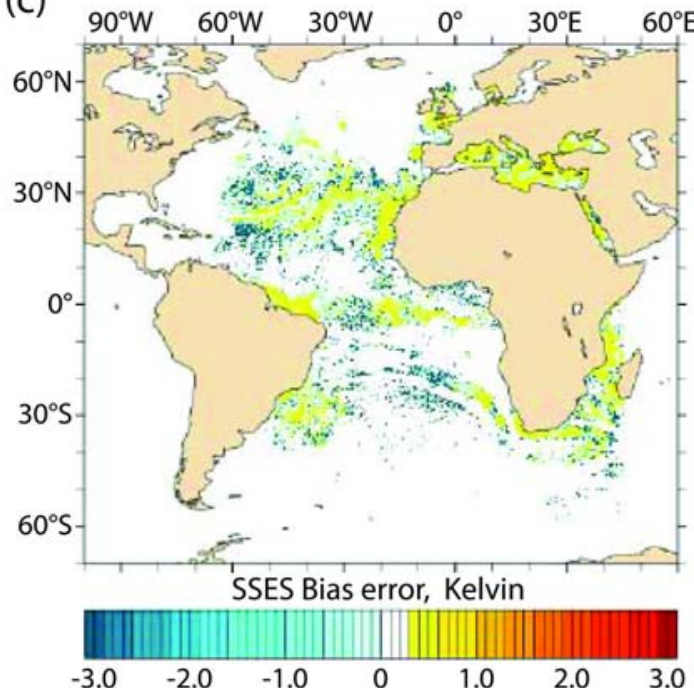

(e) $\quad 90^{\circ} \mathrm{W} \quad 60^{\circ} \mathrm{W} \quad 30^{\circ} \mathrm{W} \quad 0^{\circ} \quad 30^{\circ} \mathrm{W} \quad 60^{\circ} \mathrm{E}$

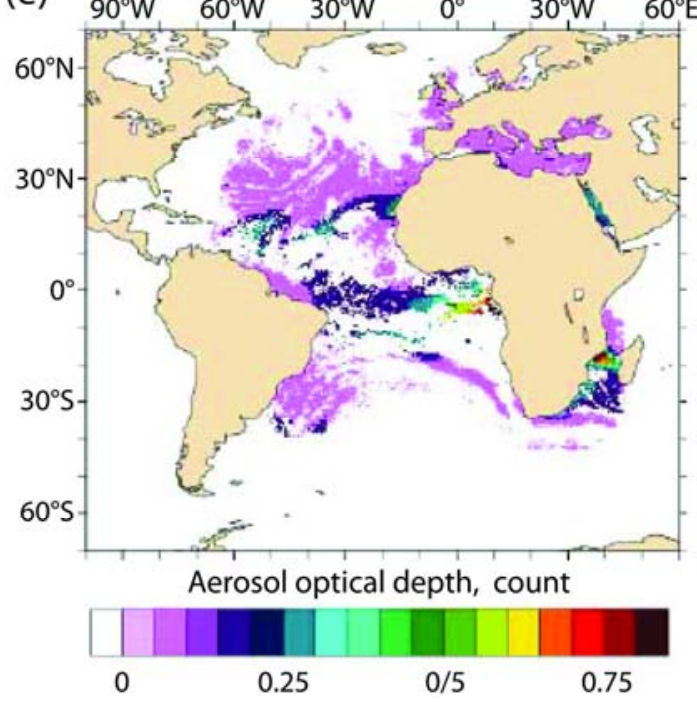

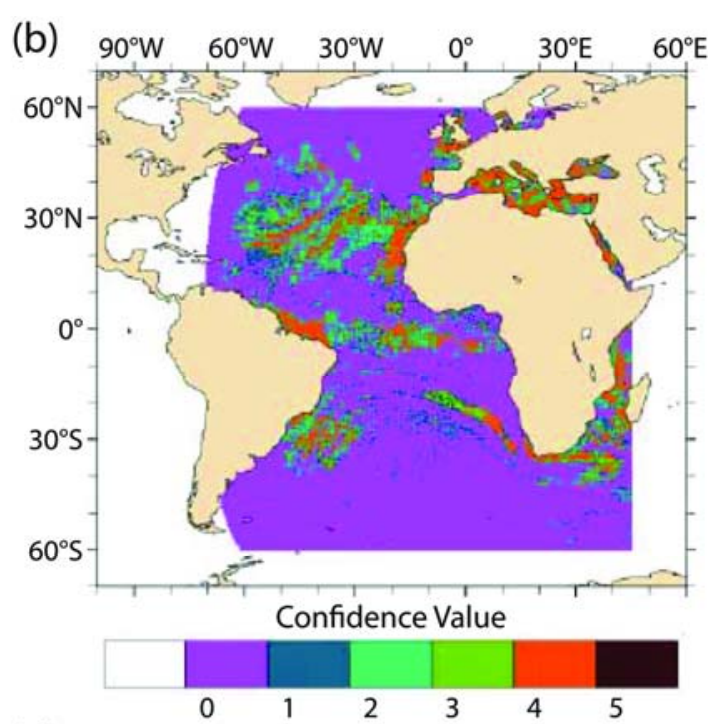

(d)
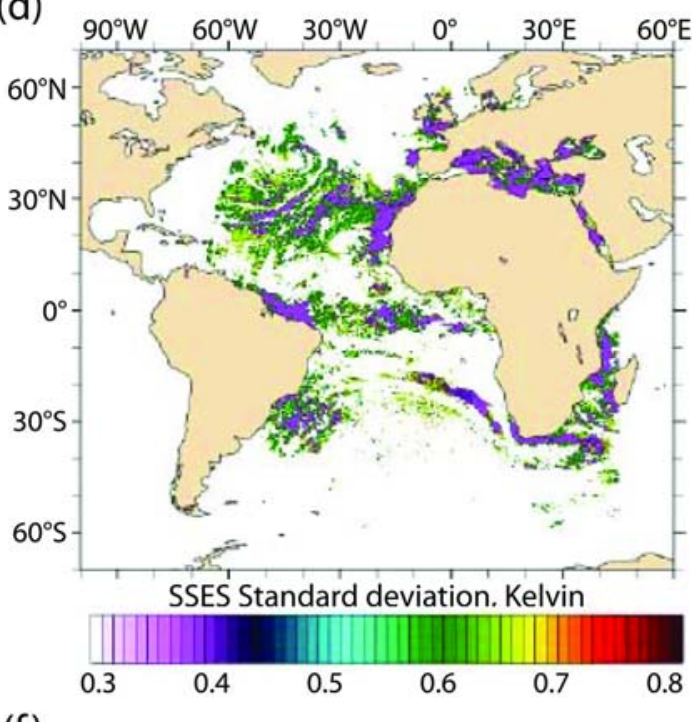

(f) $90^{\circ} \mathrm{W}, 60^{\circ} \mathrm{W}, 30^{\circ} \mathrm{W}, 0^{\circ}, 30^{\circ} \mathrm{E}, 60^{\circ} \mathrm{E}$

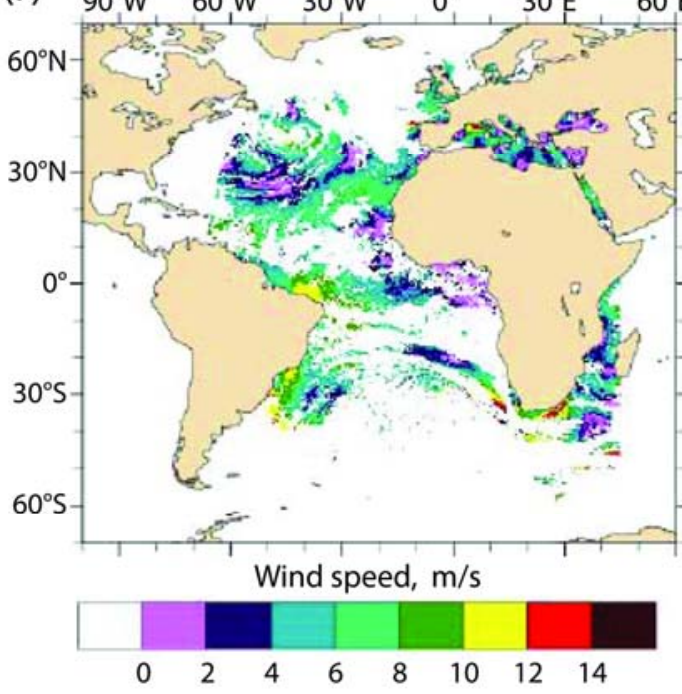

Figure 3. Example of the content of an L2P file, in this case showing data from SEVIRI. (a) SST as originally produced by the Eumetsat Oceans and Sea Ice Satellite Applications Facility (OSI SAF). (b) Confidence value. (c) Bias. (d) Standard deviation. (e) Aerosol optical depth. (f) Wind speed. Note that fields (a) - (d) represent the mandatory contents of an L2P Core file.The remaining ancillary fields are included in the full L2P files. 


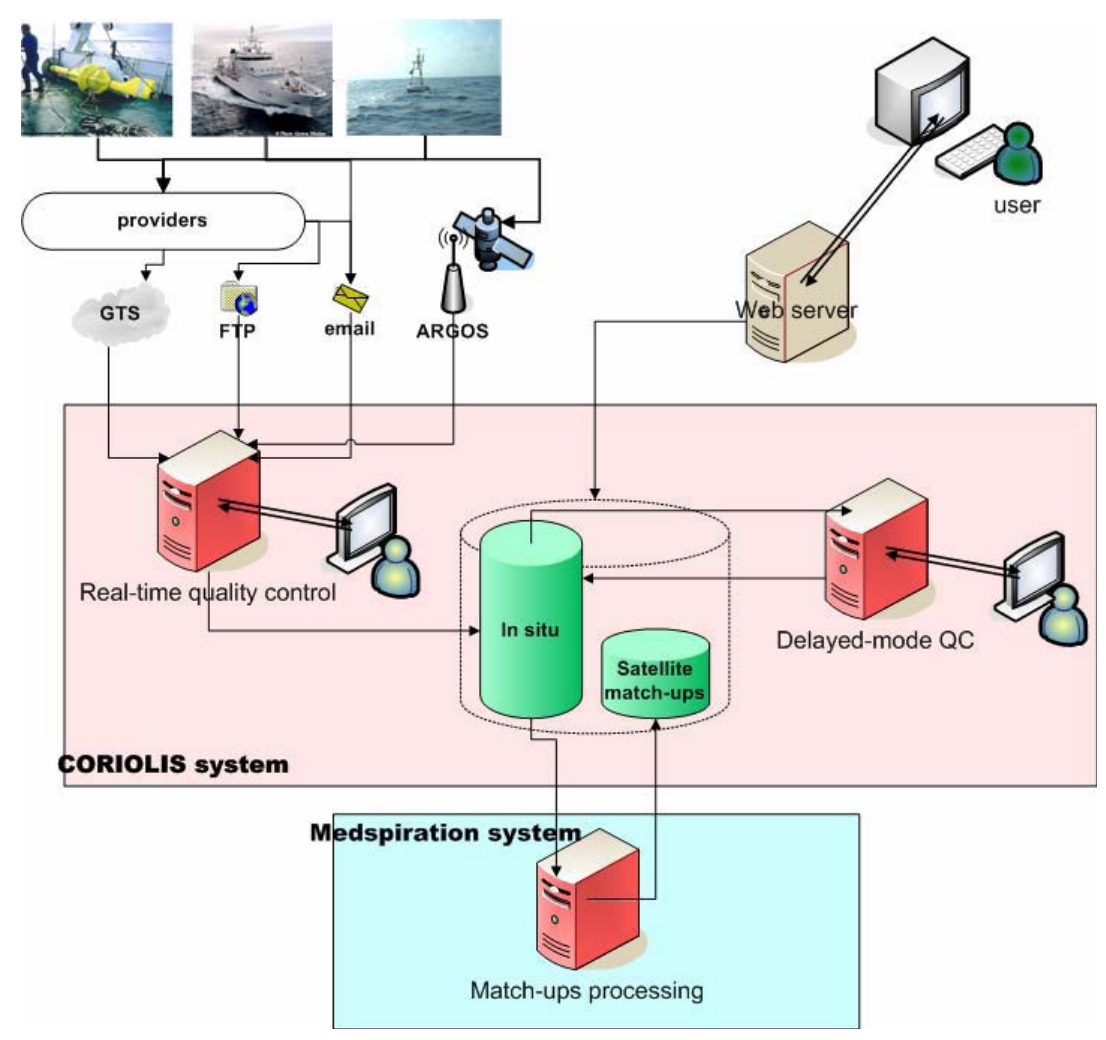

Figure 4. Integrated view of the Ifremer match-up database (MDB)system

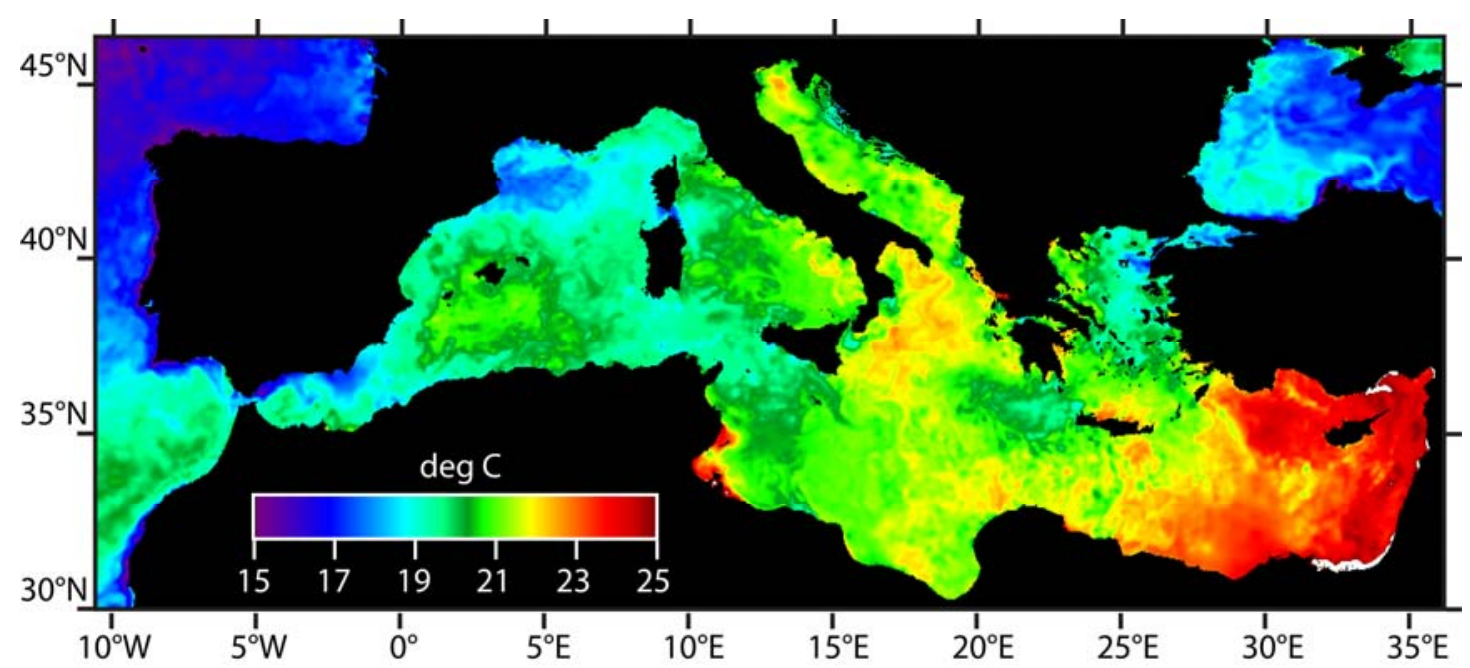

Figure 5. Medspiration L4 SST analysis of Mediterranean Sea for $5^{\text {th }}$ June 2008 


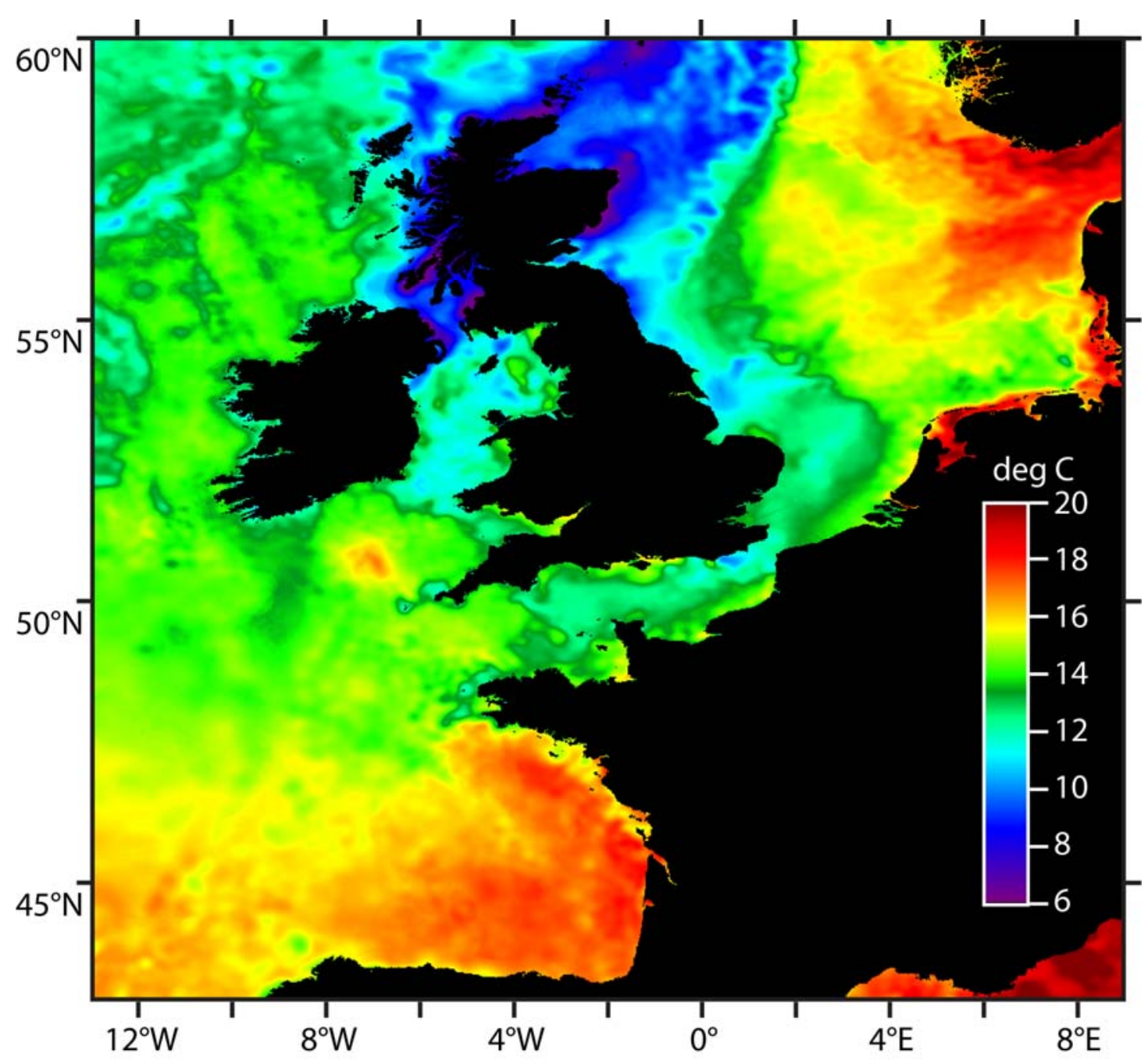

Figure 6. Medspiration L4 SST analysis of N.W. European Seas for $8^{\text {th }}$ June 2008 


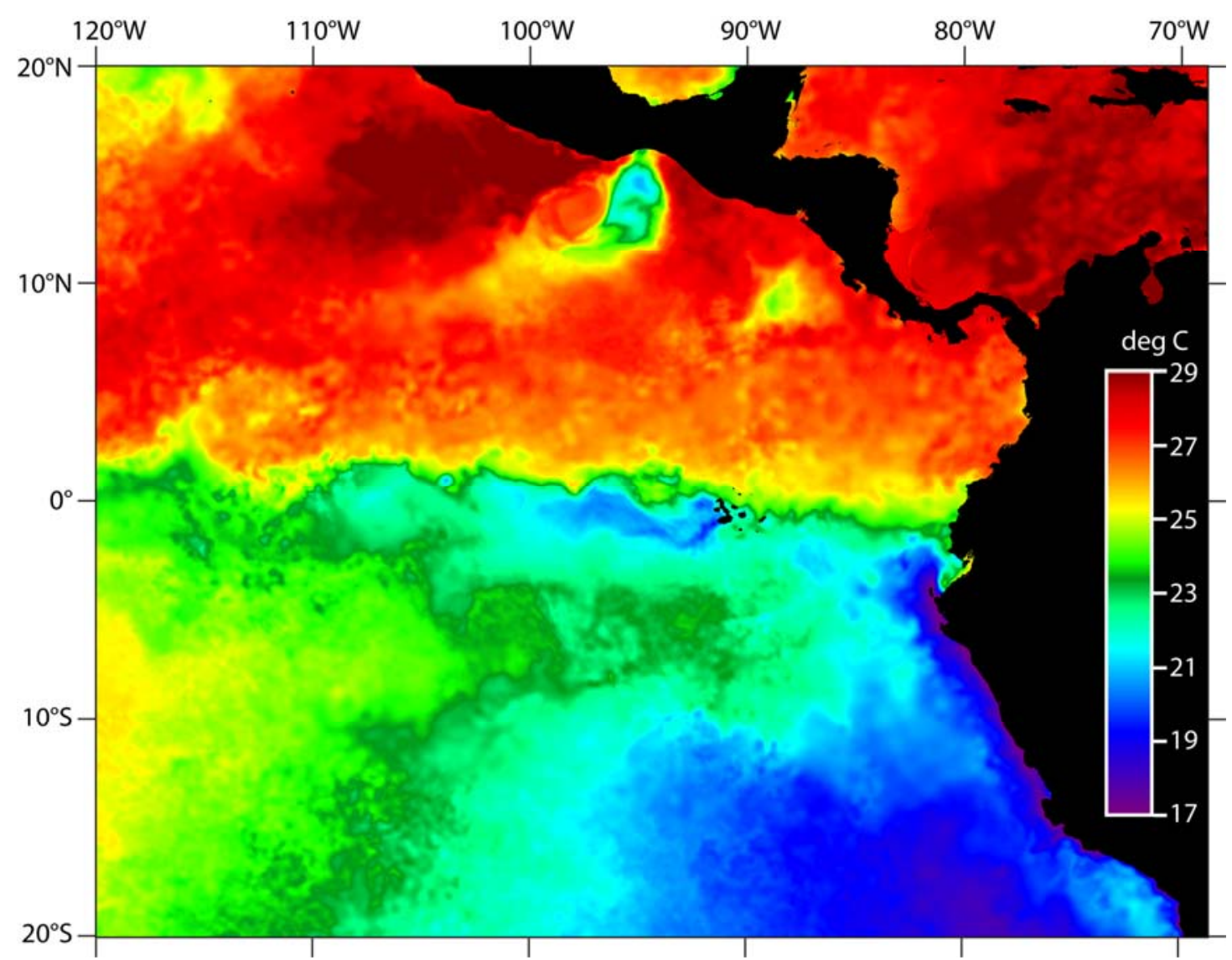

Figure 7. Medspiration L4 SST analysis of Galapagos region for $22^{\text {nd }}$ Nov 2008

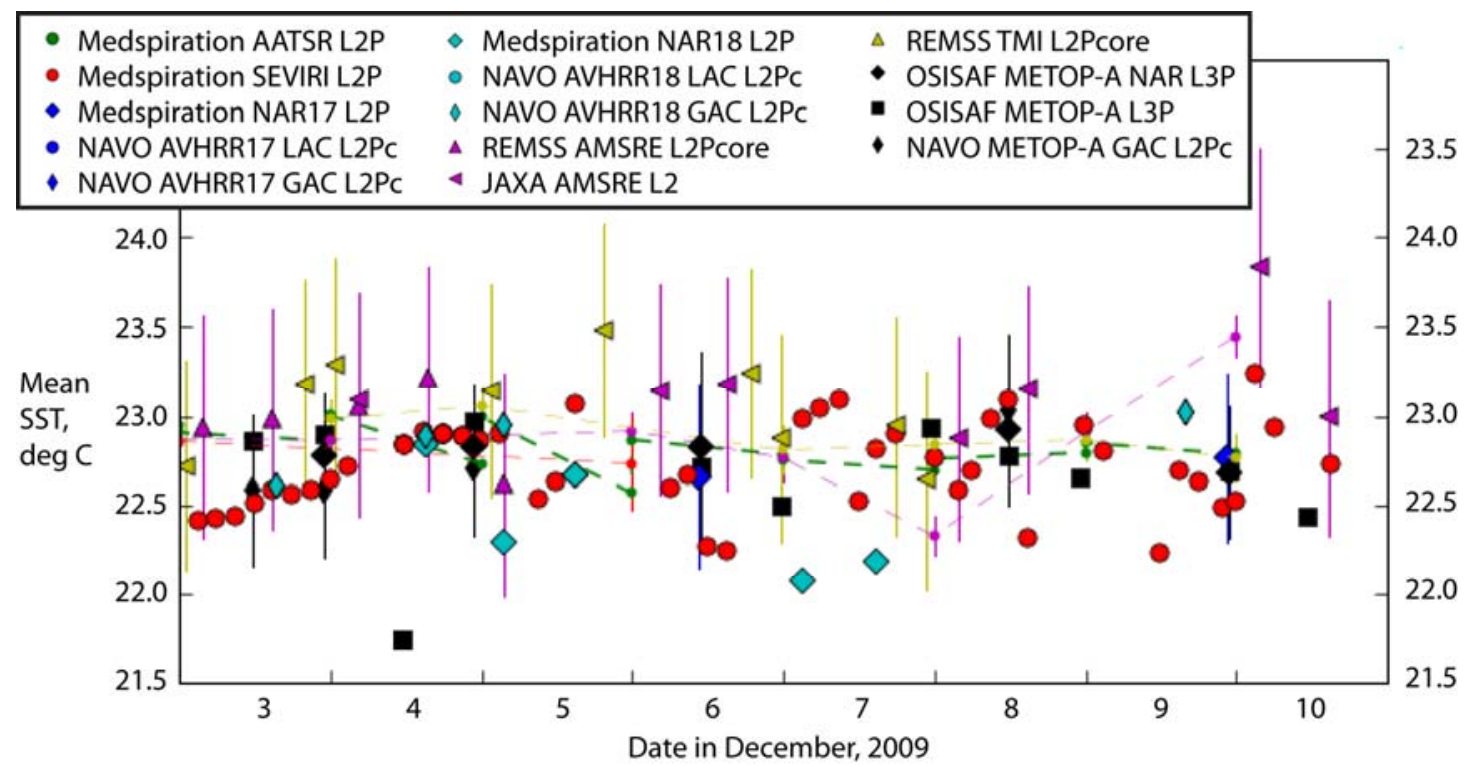

Figure 8. Records of all available satellite SST records acquired for a DDS site (ghr003) in the North Atlantic for ten days in December 2009. The values shown are the mean over the $2^{\circ} \times 2^{\circ}$ area centred at $\left[30^{\circ} \mathrm{N}, 30^{\circ} \mathrm{W}\right]$ 


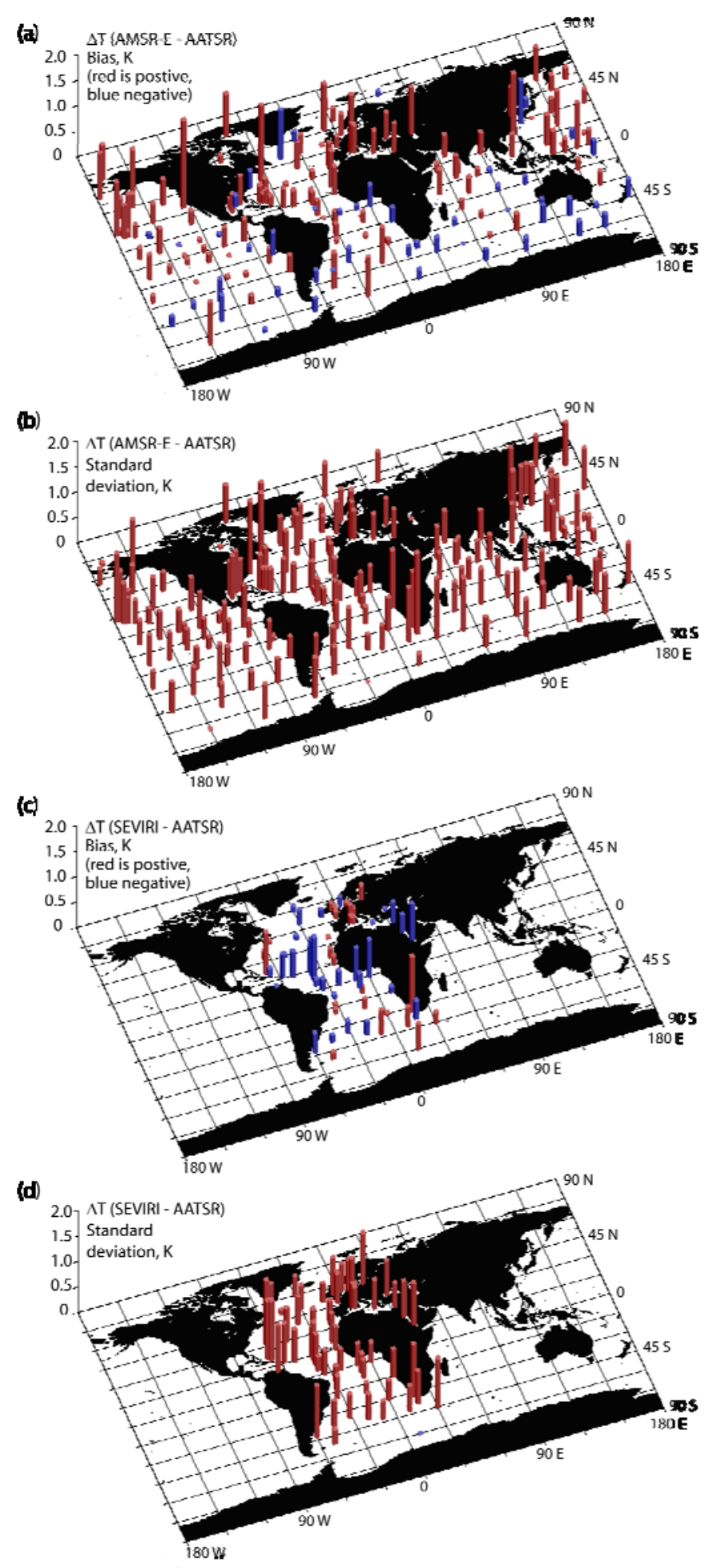

Figure 9. The mean (a) and (c) and standard deviation (b) and (d) of differences between a year of nearly coincident SST data from AMSRE and AATSR (a and b) and SEVIRI and AATSR (c and d) The vertical scale is between 0 and $2 \mathrm{~K}$. Red bars represent positive biases relative to AATSR and blue are negative. [Note that these comparisons apply to the retrieval algorithms applicable in 2007 and should not be taken to represent the current relative performance of these SST products.] 


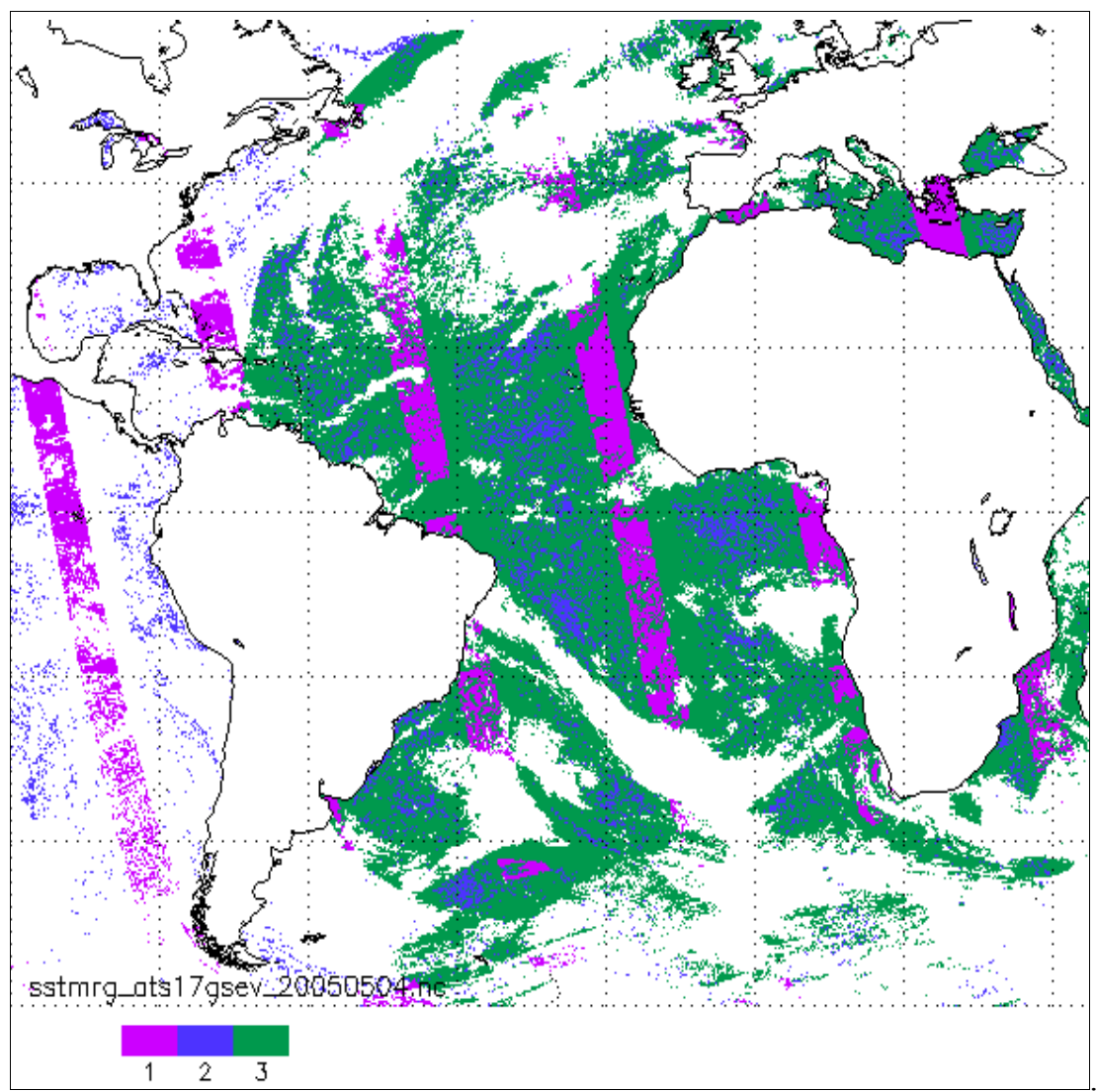

Figure 10. The L2P night data available for an SST analysis on 4 May 2005, with priority order of selecting input from AATSR (1, purple), AVHRR-17 GAC (2, blue) and SEVIRI (3, green). 

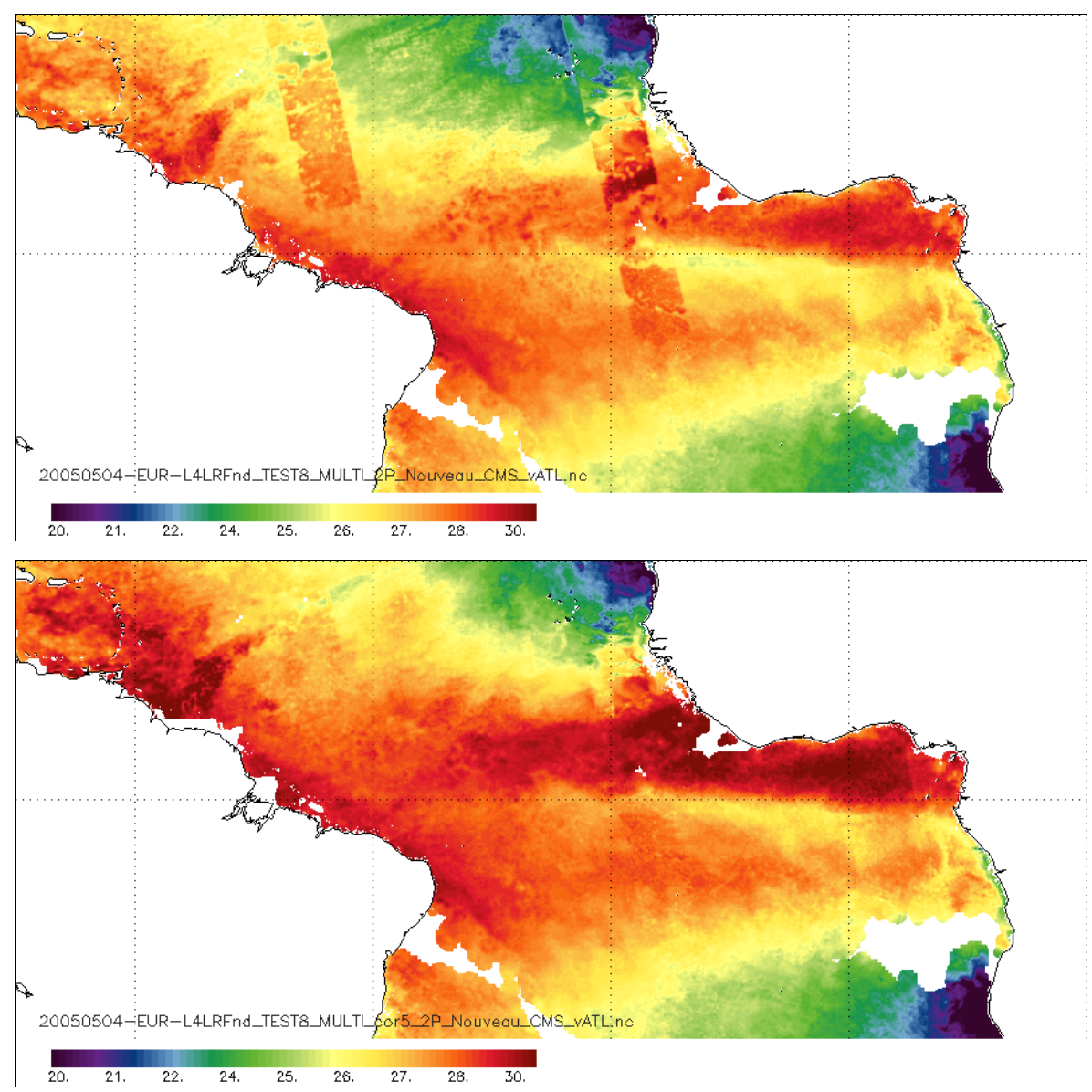

Figure 11. Results of collating SST data (scale units are deg C) using the inputs defined in Figure 10, (a) when no bias correction is applied (upper panel); (b) when bias correction to AATSR as a reference standard is applied over a 5-day window (lower panel).

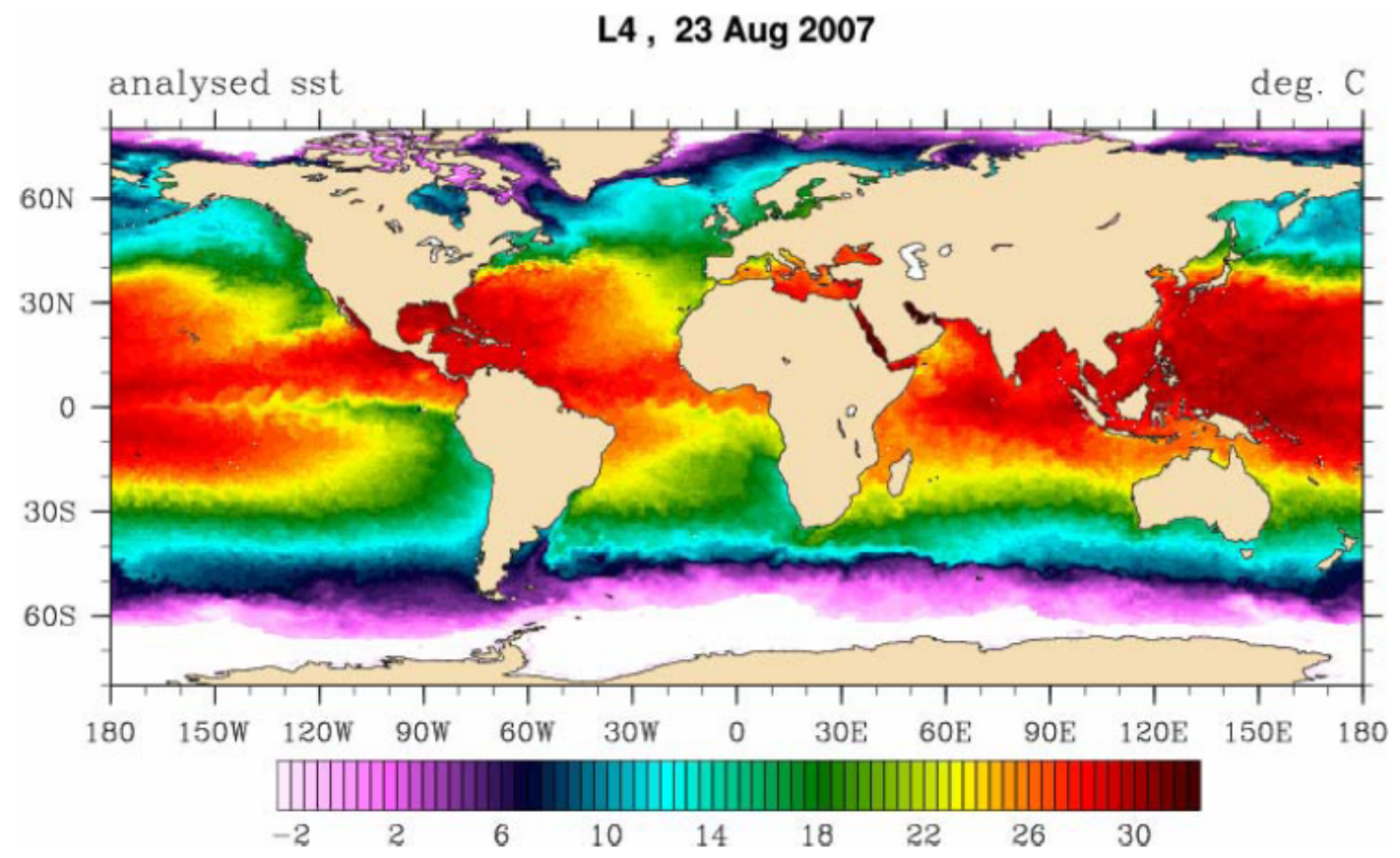

Figure 12. MERSEA real time global analysis of SST (in deg C), 23 August, 2007 